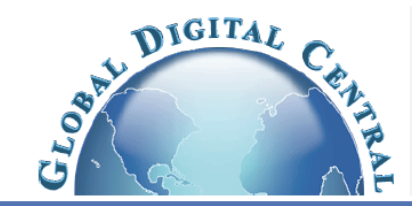

Frontiers in Heat and Mass Transfer

Available at www.ThermalFluidsCentral.org

\title{
HEAT TRANSFER CHARCACTERISTICS IN A COPPER MICRO-EVAPORATOR AND FLOW PATTERN-BASED PREDICTION METHOD FOR FLOW BOILING IN MICROCHANNELS
}

\author{
Etienne Costa-Patry ${ }^{\mathrm{a}}$, Jonathan Olivier ${ }^{\mathrm{b}}$, John R. Thome ${ }^{\mathrm{a}, *}$ \\ ${ }^{a}$ Heat and Mass Transfer Laboratory (LTCM), École Polytechnique Fédérale de Lausanne (EPFL), CH-1015 Lausanne, Switzerland \\ ${ }^{\mathrm{b}}$ Photovoltaic Technology Intellectual Property (Pty) Ltd, South Africa
}

\begin{abstract}
This article presents new experimental results for two-phase flow boiling of R-134a, R-1234ze(E) and R-245fa in a micro-evaporator. The test section was made of copper and composed of 52 microchannels $163 \mu \mathrm{m}$ wide and $1560 \mu \mathrm{m}$ high with the channels separated by $178 \mu \mathrm{m}$ wide fins. The channels were $13.2 \mathrm{~mm}$ long. There were 35 local heaters and temperature measurements arranged in a $5 \times 7$ array as a pseudo-CPU. The total pressure drops of the test section were below $20 \mathrm{kPa}$ in all cases. The wall heat transfer coefficients were generally above $10^{\prime} 000 \mathrm{~W} / \mathrm{m}^{2} \mathrm{~K}$ and a function of the heat flux, vapor quality and mass flux. A new flow pattern-based prediction method for flow boiling heat transfer coefficients in microchannels was developed based on the experimental results. The new prediction method also predicted published data for four other test sections accurately, capturing the trends versus vapor quality well.
\end{abstract}

Keywords: Two-phase microchannel flow, Microcooling, Flow pattern-based prediction method

\section{INTRODUCTION}

Electronic applications offer the economical potential to be the heat source for low temperature $\left(\leq 100^{\circ} \mathrm{C}\right)$ waste recovery systems because they generate a very large amount of heat. Currently air-cooled systems are commonly used for computers and IGBTs (Insulated Gate Bipolar Transistors). Yet for these applications, air-cooling is expensive. Koomey et al. (2009) have calculated that the annual cost of running an air-cooled data center is currently as high as the annualized equipment costs.

Two-phase cooling is an optimal replacement to air-cooling: the latent heat of evaporation of a refrigerant $(\approx 150 \mathrm{~kJ} / \mathrm{kg})$ is much greater than the sensible heat of liquid water $(4.2 \mathrm{~kJ} / \mathrm{kg})$. Therefore, it requires a much lower flow rate and pumping power to remove the same amount of heat than air or water. In addition, the fluid temperature of two-phase flow can be almost uniform whilst using a dielectric refrigerant removes the risk associated with water in an electrical circuit. Finally, two-phase cooling can be directly integrated into a heat pump cycle, which can efficiently increase the value of the waste heat for further use by raising the system's output temperature.

Any such heat recovery system must start from the two-phase liquidvapor flow leaving the evaporator mounted on the heat generating chip. Park and Thome (2010) have shown that with a copper micro-evaporator, an evaporating flow of refrigerant can successfully dissipate heat fluxes over $350 \mathrm{~W} / \mathrm{cm}^{2}$ while maintaining the operating temperature under a given temperature limit, typically $85^{\circ} \mathrm{C}$ for CPUs and $125^{\circ} \mathrm{C}$ for IGBTs. Current high-end CPU applications have a heat load of around $35 \mathrm{~W} / \mathrm{cm}^{2}$ which is expected to rise in the next generation of chips to about 100$150 \mathrm{~W} / \mathrm{cm}^{2}$, while IGBTs have local heat fluxes above $120 \mathrm{~W} / \mathrm{cm}^{2}$. The temperature limitation is principally set to reduce risk of failure by electromigration in micro-electronics nanometer-sized wires.

Many studies have examined two-phase heat transfer in microchannel in single tubes or in multi-microchannel test sections. Although the data reduction for single tube experiments is simpler, especially regarding the flow distribution assumption, both types of test sections provide precise results, once proper care is taken.

Thome and Consolini (2009) categorized experimental trends for microscale heat transfer coefficients in two groups. In some studies, the heat transfer coefficient was found to be unaffected by the vapor quality or the mass flux, but strongly dependent on the heat flux (Lazarek and Black (1982); Tran et al. (1996); Bao et al. (2000)). In a second group of studies, heat transfer coefficients were found to be a function of the vapor quality and the heat flux. The heat transfer results of Lin et al. (2001) for R-141b in a 1mm tube and Agostini et al. (2008) for R-236fa in a silicon $680 \mu \mathrm{m} \times 223 \mu \mathrm{m}$ multi-microchannel evaporator vary with respect to heat flux and vapor quality. As the heat flux increases, the mean heat transfer increases. First the local heat transfer tends to be higher

*Corresponding author. Email: john.thome@epfl.ch 
towards the end of the channel, at high vapor qualities, but at higher heat flux, the shape of the curve changes. It takes on a V-shape or flattens and later has a decreasing trend with vapor quality. The two first trends are also clearly seen in the results of Ong and Thome (2011b) and Costa-Patry et al. (2011b).

Predicting experimental two-phase heat transfer coefficients in microchannels and their trends is a complicated task, taking into account that the reported experimental values range from 2000 to $50^{\prime} 000 \mathrm{~W} / \mathrm{m}^{2} \mathrm{~K}$. Nevertheless, several prediction methods have been proposed. The most interesting ones were written with the insight from several studies, fluids and geometries. Some studies adapted macroscale methods, such as Bertsch et al. (2009). Thome et al. (2004) developed a semi-mechanistic model, named the three-zone model, to describe the evaporation of elongated bubbles in microchannels. For the annular flow regime, the method of Cioncolini and Thome (2011) predicts both macro and microscale heat transfer coefficients. It is derived from a mechanistic analysis of the annular flow and used experimental results for $1.03 \mathrm{~mm}$ to $14.4 \mathrm{~mm}$ diameter test sections to optimize the method's accuracy.

The objectives of the present paper are in a first part to present new experimental results for pressure drops and heat transfer coefficients obtained in a multi-microchannel copper evaporator. In a second part, an improvement on the three-zone model of Thome et al. (2004) will be presented. It will then be integrated into a new flow pattern-based prediction method for two-phase heat transfer in microchannels.

\section{EXPERIMENTAL SETUP}

The experimental setup used a thermal chip designed to be able to mimic the behavior of a computer chip and make local temperature and heat transfer coefficient measurements. It was previously used for a study with a silicon micro-evaporator by Costa-Patry et al. (2011c), where it was thoroughly described. A schematic of the test package is shown in Fig 1 along with the relevant dimensions, listed in Table 1 . In the package only the evaporator and the manifold are new. In addition, for the current experimental campaign, the mounting of the heater was modified (Costa-Patry (2011)), but this has no influence on the experiments.

The copper evaporator was manufactured by Wolverine Tube Inc. using their micro-deformation technology. It was composed of 52 channels, each $163 \mu \mathrm{m}$ wide and $1560 \mu \mathrm{m}$ high, with fins $178 \mu \mathrm{m}$ thick. The hydraulic diameter was measured by image processing of the channel cut view. Since the channels were not perfectly rectangular, the area to perimeter ratio was smaller and the tradional hydraulic diameter was measured as $246 \mu \mathrm{m}$. The value for $D_{h}=\frac{2 W H}{W+H}$ defined as $294 \mu \mathrm{m}$. The total channel length was $15.7 \mathrm{~mm}$ and restrictions were formed at the channel extremities. The inlet restriction was $0.5 \mathrm{~mm}$ wide, the outlet restriction was $2.0 \mathrm{~mm}$ and the effective channel length was $13.2 \mathrm{~mm}$. The channels were thus $0.5 \mathrm{~mm}$ longer than the thermal chip $(12.7 \mathrm{~mm})$. This extra length was positioned at the channel outlet and was accounted for in postprocessing.

The test section's manifold was made of stainless steel. It was in contact with the evaporator on two planes. The manifold was pressed on the evaporator to close the top of the channels. On the edges, an O-ring sealed the test section. The inlet and outlet slits, respectively $0.5 \mathrm{~mm}$ and $2 \mathrm{~mm}$ wide, were machined in the manifold up to the plenums, both $4.5 \mathrm{~mm}$ in diameter. Two openings were made in each plenum at mid-height for temperature and pressure measurements. In addition, two $0.5 \mathrm{~mm}$ pressure tap holes were made on top of the evaporator at $2.73 \mathrm{~mm}$ and $11.72 \mathrm{~mm}$ from the inlet edge. They were positioned over Columns 2 and 6 , respectively $3.70 \mathrm{~mm}$ and $13.82 \mathrm{~mm}$ away for column 1 edge, and recorded pressure over two channels at most.

\section{OPERATING CONDITIONS}

Three refrigerants were used for the tests, R-134a, R-1234ze(E) and R$245 \mathrm{fa}$. R-1234ze(E) is produced by Honeywell International as a sub-

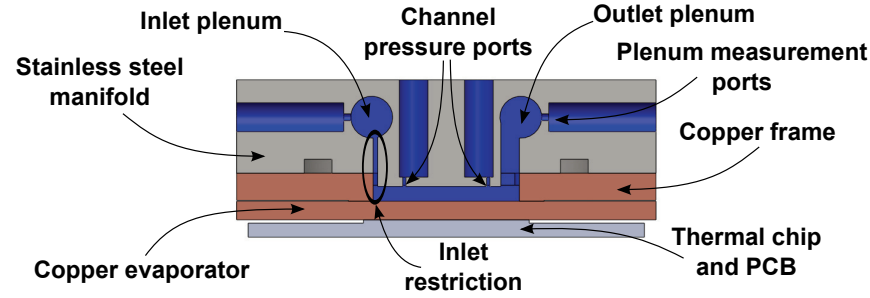

(a) Cut views along the channel axis. Blue: Sections filled with refrigerant.

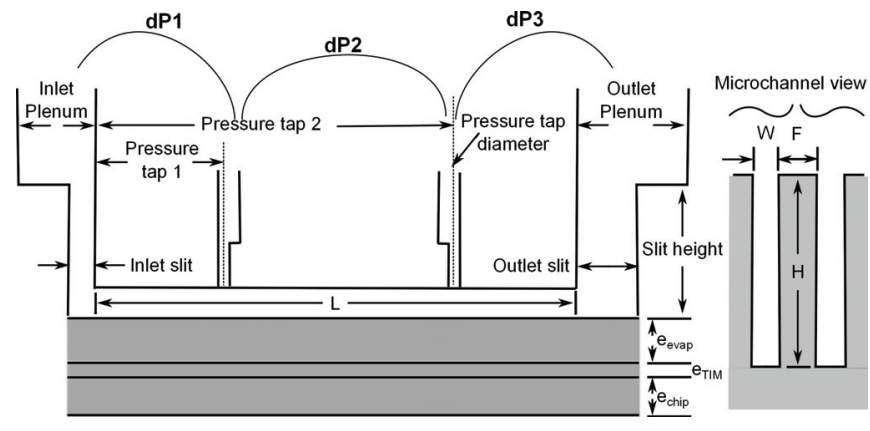

(b) Position of the dimensions

Fig. 1 Schematic of the test sections.

stitute for R-134a and was donated to LTCM. It has a low greenhouse warming potential compared to the others and its properties are similar to R-134a. Tests were performed at two saturation temperatures: $30^{\circ} \mathrm{C}$ and $50^{\circ} \mathrm{C}$. A needle valve placed before the test section maintained a low subcooling in the inlet plenum $\left(<1^{\circ} \mathrm{C}\right)$. The inlet restriction then partially flashed the fluid providing vapor bubbles to start the boiling process. Pressure and temperature measurements in the plenums were in close agreement with respect to the saturation point predicted by the vapor pressure curve. Uncertainties of all measurements were calculated by means of the method of Kline and McClintock (1953) and are summarized in Table 2. Fluid properties and vapor pressure curves were obtained with REFPROP, the NIST Standard Reference Database 23, Version 8.0.

\section{DATA REDUCTION}

To calculate local heat transfer coefficients the local channel pressure and the local heat flux must be derived from the measurements. In the test section, there are three different surfaces relevant to heat transfer:

1. Base: Surface found at the bottom of the thermal package, where the heaters are positioned

2. Footprint: Equivalent surface found at the root of the fins, when the fins are removed

\section{Wall: Entire surface in contact with the fluid}

Due to the high thermal conductivity of copper, the effect of heat spreading within the evaporator are important, such that the base and footprint heat fluxes are different. This was taken into account using a multi-dimensional thermal conduction scheme, previously used to compute heat transfer coefficients in non-uniform heat flux conditions in a silicon micro-evaporator (Costa-Patry et al. (2011a)). As a result, the local footprint heat fluxes and temperatures are known.

\subsection{Pressure drop}

In the test section, each component of the total pressure was measured, but due to geometrical constraints, it was not possible to directly place 
Table 1 Test section dimensions.

\begin{tabular}{|c|c|c|}
\hline & Dimension & Uncertainty \\
\hline B: Evaporator width(mm) & 17.78 & \pm 0.1 \\
\hline $\mathrm{L}_{c h}:$ Channel length(mm) & 13.2 & \pm 0.1 \\
\hline 1: Heater size $(\mathrm{mm})$ & 2.54 & \pm 0.02 \\
\hline $\mathrm{H}$ : Channel height $(\mu \mathrm{m})$ & 1560 & \pm 5 \\
\hline W: Channel width $(\mu \mathrm{m})$ & 163 & \pm 5 \\
\hline F: Fin thickness $(\mu \mathrm{m})$ & 178 & \pm 5 \\
\hline $\mathrm{N}$ : Number of channels & 52 & - \\
\hline $\mathrm{D}_{h}:$ Hydraulic diameter $(\mu \mathrm{m})$ & 246 & \pm 10 \\
\hline $\mathrm{e}_{\text {chip }}:$ Thermal chip thickness $(\mu \mathrm{m})$ & 350 & \pm 5 \\
\hline $\mathrm{e}_{T I M}:$ TIM thickness $(\mu \mathrm{m})$ & 40 & \pm 15 \\
\hline $\mathrm{e}_{\text {evap }}$ : Evaporator base thickness $(\mu \mathrm{m})$ & 1800 & \pm 10 \\
\hline Wall roughness $(\mathrm{nm})$ & 450 & \pm 10 \\
\hline Inlet slit width $(\mathrm{mm})$ & 0.5 & \pm 0.1 \\
\hline Outlet slit width(mm) & 2.0 & \pm 0.1 \\
\hline Slit height (mm) & 6.67 & \pm 0.05 \\
\hline Inlet plenum width $(\mathrm{mm})$ & 4.5 & \pm 0.05 \\
\hline Outlet plenum width(mm) & 4.5 & \pm 0.05 \\
\hline Pressure tap diameter(mm) & 0.5 & \pm 0.05 \\
\hline $\mathrm{L}_{P T a p 1}$ : Pressure tap position $1(\mathrm{~mm})$ & 2.73 & \pm 0.01 \\
\hline $\mathrm{L}_{P T a p 2}:$ Pressure tap position $2(\mathrm{~mm})$ & 11.72 & \pm 0.01 \\
\hline
\end{tabular}

Table 2 Results of the error propagation analysis.

\begin{tabular}{|c|c|c|}
\hline & Value & Uncertainty \\
\hline Base heat flux $\left(\mathrm{kW} / \mathrm{m}^{2}\right)$ & $130-2950$ & $\pm 2 \%$ \\
Mass flux $\left(\mathrm{kg} / \mathrm{m}^{2} \mathrm{~s}\right)$ & $205-569$ & $\pm 3 \%$ \\
Inlet restr. pressure drop $(\mathrm{kPa})$ & $0.05-1$ & $\pm 6 \%$ \\
Outlet restr. pressure drop $(\mathrm{kPa})$ & $-0.5-3.5$ & \pm 0.5 \\
Channel pressure drop TP $(\mathrm{kPa})$ & $1-12$ & \pm 0.5 \\
Vapor quality & $0-0.8$ & $\pm 0.01-0.05$ \\
Wall heat transf. coeff. $\left(\mathrm{W} / \mathrm{m}^{2} \mathrm{~K}\right)$ & $5000-27 ’ 000$ & $\pm 3-15 \%$ \\
\hline
\end{tabular}

the pressure tap at $\mathrm{z}=0$ and $\mathrm{z}=\mathrm{L}_{c h}$. To evaluate the inlet restriction pressure drop, a series of single-phase test were performed. The single-phase channel pressure drop $\left(\Delta \mathrm{P}_{2}\right)$ was then extrapolated linearly to determine the inlet restriction pressure drop. The resulting equation was:

$$
\Delta p_{\text {restr-in }}=\Delta p_{1}-\frac{\Delta p_{2}}{L_{P T a p 2}-L_{P T a p 1}} \times L_{P T a p 1}
$$

The two-phase outlet restriction pressure drop was calculated during the two-phase experiment using the same technique:

$$
\Delta p_{\text {restr-out }}=\Delta p_{3}-\frac{\Delta p_{2}}{L_{P T a p 2}-L_{P T a p 1}} \times\left(L_{c h}-L_{P T a p 2}\right) ;
$$

A two-phase linear pressure drop was assumed to describe the local channel pressures. The channel length was discretized into 100 increments $i$. The first channel pressure, $\mathrm{p}_{1, y}$, was calculated by subtracting the inlet restriction pressure drop from the inlet plenum absolute pressure:

$$
p_{1, y}=p_{\text {inlet }}-\Delta p_{\text {restr-in }}
$$

If the liquid entering the channel was sub-cooled, the local pressure drop was computed using:

$$
p_{i, y}=p_{i-1, y}-4 f \frac{G^{2}}{2 \rho_{l}} \frac{d z}{D_{h}}
$$

where $f$ was evaluated using Biber and Belady (1997)'s correlation .

Once the fluid's saturation temperature was reached, the position

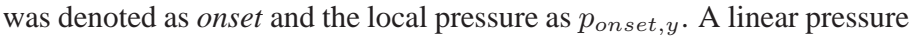
drop rate was assumed between $p_{\text {onset, } y}$ and a reference pressure, $p_{r e f, y}$.

$$
p_{i, y}=p_{\text {onset }, y}-d z(i-\text { onset }) \frac{p_{\text {onset }, y}-p_{\text {ref }, y}}{z_{\text {ref }, y}-z_{\text {onset }}}
$$

The reference was set to pressure tap 2:

$$
p_{\text {ref }, y}=p_{\text {outlet }}-\Delta p_{3}
$$

The local fluid enthalpy was calculated from an energy balance and the inlet restriction was assumed to be adiabatic, so that:

$$
\begin{gathered}
h_{1, y}=h_{i n} \\
h_{i, y}=h_{i-1, y}+q_{\text {footprint }, x y} \frac{W+F}{G H W} d z
\end{gathered}
$$

Using local pressure and temperature in REFPROP to determine the reference enthalphy $\mathrm{h}_{l}$ and $\mathrm{h}_{v}$, the local vapor quality was obtained:

$$
x_{i y}=\frac{h_{i y}-h_{l, i y}}{h_{v, i y}-h_{l, i y}} .
$$

Finally, the local fluid temperature was determined in REFPROP using the local pressure (and enthalpy for single-phase).

\subsection{Heat transfer coefficient}

With the local footprint heat flux and the fluid and wall temperatures, the footprint heat transfer coefficient can be calculated from Newton's law of cooling:

$$
\alpha_{\text {footprint }, x y}=\frac{q_{\text {footprint }, x y}}{T_{w, x y}-T_{f, x y}} .
$$

As previously noted, the calculation of the fluid temperature was divided into 100 increments, whereas there were 5 base temperature measurements in each column. Thus for the calculation of the heat transfer coefficient, the average of the 20 local fluid temperatures found over each heater was used.

The footprint heat transfer coefficient $\left(\alpha_{\text {footprint }}\right)$ is useful for thermal resistance analysis in thermal packaging. However, to compare results to flow boiling prediction methods and design an evaporator, information about the wall heat transfer coefficient, which includes the influence of the fins, is needed. The local wall heat flux and wall heat transfer coefficient were calculated by iteratively solving equations $11-13$, adapted from Kreith and Bohn (2001) for N+1 fins:

$$
q_{w, x y}=q_{\text {footprint }, x y} \frac{(N+1)(F+W)-W}{N W+2(N+1) H \eta_{w, x y}}
$$

with

$$
\eta_{w, x y}=\frac{\tanh \sqrt{2 \alpha_{w, x y} \frac{(H)^{2}}{\lambda_{\text {evap }} F}}}{\sqrt{2 \alpha_{\text {footprint }, x y} \frac{(H)^{2}}{\lambda_{\text {evap } F}}}}
$$

and

$$
\alpha_{w, x y}=\frac{q_{w, x y}}{T_{w, x y}-T_{f, x y}} .
$$

\section{PRESSURE DROP RESULTS}

Pressure measurements were taken at different locations in the test sections in order to evaluate the following pressure drop components: the inlet restriction pressure drop, the microchannel pressure drop and the outlet restriction pressure drop. Added together, they formed the total pressure drop across the test section. 


\subsection{Validation test}

Single-phase microchannel pressure drops in the test section were used to validate the measurement and data reduction methods. Using the same measurement datasets as the one used to determine the inlet pressure loss coefficient, Fig 2 shows that the experimental channel frictional pressure drop factor is very well predicted by the method of Biber and Belady (1997). Only a few measurement points below $\mathrm{Re}=100$ are not accurate. Thus the channel pressure drop measurement technique is validated.

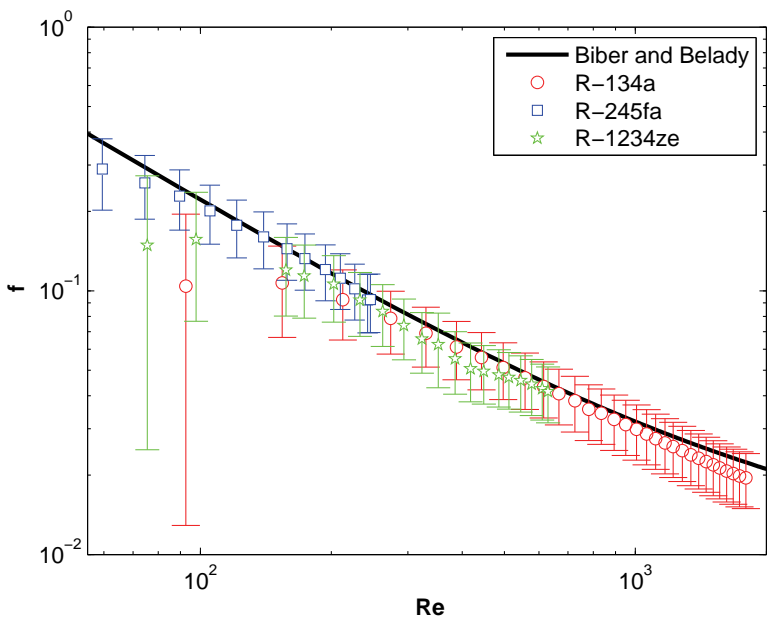

Fig. 2 Frictional pressure drop factor for copper test section.

\subsection{Inlet and outlet restriction pressure drop}

The pressure drop found in the inlet restriction was evaluated for each refrigerant in single-phase adiabatic conditions. It covers pressure drops from 50 to $1000 \mathrm{~Pa}$. The measurements were repeated for several mass fluxes and using a standard formulation used by Idelcik (1999) for singularity pressure loss, the inlet restriction losses were modeled as:

$$
\Delta p_{\text {restr-in }}=\frac{G^{2}}{2 \rho_{l}} \xi
$$

where $\xi$ is the pressure loss coefficient. This expression was then used for the two-phase experiments, although the restriction, by flashing the incoming liquid as it exits the restriction, increased the pressure drop. This added pressure component was assumed to be negligible when compared to the two-phase channel pressure drop.

Fig 3 shows the curves for all fluids for the different experimental test conditions. The best fit values for $\xi$ are respectively 5.708, 6.399 and 6.563 for R-134, R-1234ze(E) and R-245fa.

To obtain an estimate of $\xi$ without experimentation, Idelcik (1999) lists pressure loss coefficients for simplified geometries (sudden expansion, round to square pipe, etc...). The inlet restrictions of the test sections must be divided into three sections to fit into the Idelcik (1999) description. The flow first enters a sudden contraction, when it goes from the plenum to the slit. Then it flows through a second area reduction, when entering the channels from top, and finally it makes a right angle turn into the channels. The pressure loss coefficient for each section was then calculated for a channel-based mass flux of $500 \mathrm{~kg} / \mathrm{m}^{2} \mathrm{~s}$ and the results are tabulated in Table 3. The sum of the three components (8.6) is also plotted in Fig 3. Since it is relatively close to the experimental pressure drop shown Fig 3, this method can be used to evaluate the inlet restriction pressure drops for design purposes when no test data are available.

The outlet restriction pressure drop was computed using equation 2 . A result example is shown for R-134a in Fig 4. Compared to the results of

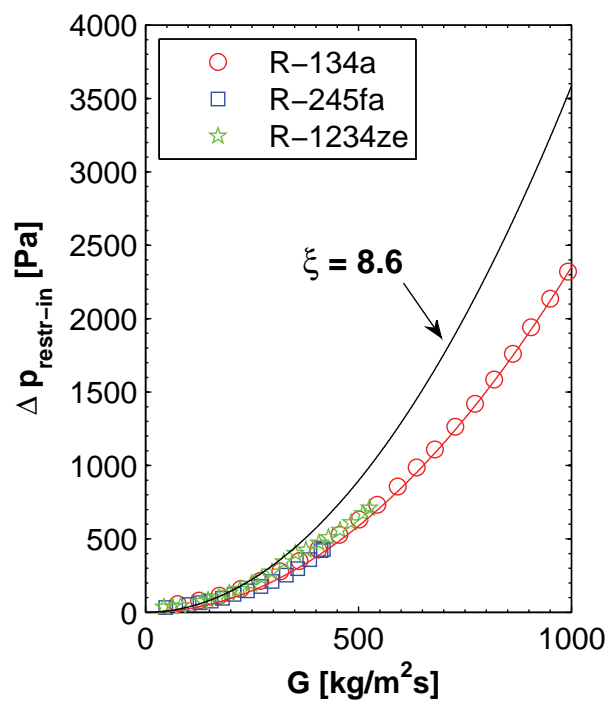

Fig. 3 Experimental measurement of the inlet restriction pressure drop

Table 3 Pressure loss coefficients $\xi$ derived from methods by Idelcik (1999).

\begin{tabular}{|c|c|}
\hline Section 1 & 1.7 \\
Section 2 & 0.4 \\
Section 3 & 6.5 \\
\hline Sum & 8.6 \\
\hline
\end{tabular}

Costa-Patry et al. (2011c), which used $85 \mu \mathrm{m}$ channels, the current pressure drops for the same fluid (R-245fa) are lower, which means that the pressure drop in the restriction is a function of the channel width. All

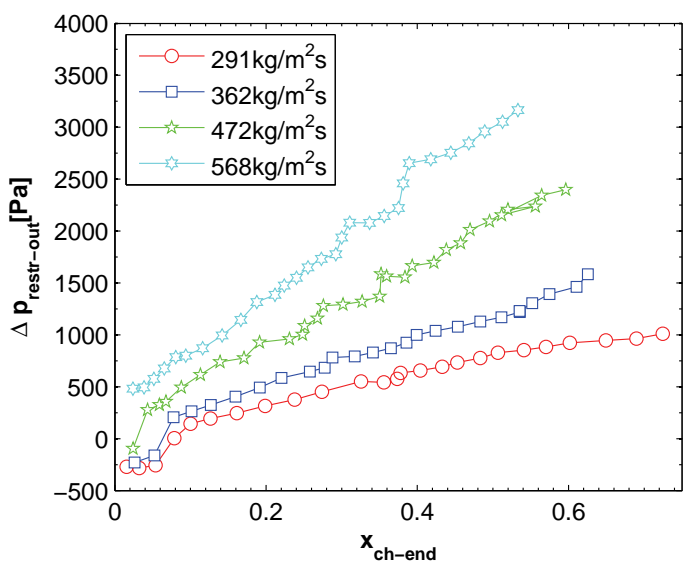

Fig. 4 Outlet restriction pressure drop for R-134a at $\mathrm{T}_{\text {sat }}=30.5^{\circ} \mathrm{C}$.

outlet restriction pressure drop measurements from this work and from Costa-Patry et al. (2011c) (585 datapoints) have been collected into a single database in order to develop a new prediction method. The following equation is giving by Collier and Thome (1994) for pressure recovery across a sudden enlargement:

$$
\Delta p_{\text {in-end }}=G_{1}^{2} \frac{A_{\text {in }}}{A_{\text {end }}}\left(1-\frac{A_{\text {in }}}{A_{\text {end }}}\right) v_{l}\left(1+\frac{v_{l v}}{v_{l}} x\right)
$$

The density ratio, geometry, vapor quality and mass flux are all present in the equation for pressure drop, but it does not predict a pressure drop from 
the inlet position to the outlet position. A simple enlargement will lead to a pressure recovery, but in the outlet restriction, the complex geometry leads to a pressure drop from the channel end to the plenum in most cases.

Starting from the Collier and Thome (1994) equation, the term $1+$ $\frac{v_{l v}}{v_{l}} x$ was simplified into $\frac{\rho_{l}}{\rho_{v}} x$. The area ratio was replaced by the channel width $\left(\mathrm{W}_{c h}\right)$ to the slit width $\left(\mathrm{W}_{\text {slit }}\right)$ ratio raised to an exponent. This exponent's value was found by numerical least-square fit iteration. The resulting equation is:

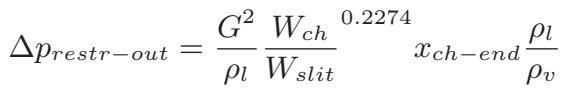

The predicted data are shown against the experimental ones in Fig 5. The mean absolute error for pressure drops larger than $500 \mathrm{~Pa}$ is $28.5 \%$ and $65.1 \%$ of all data are predicted within $30 \%$.

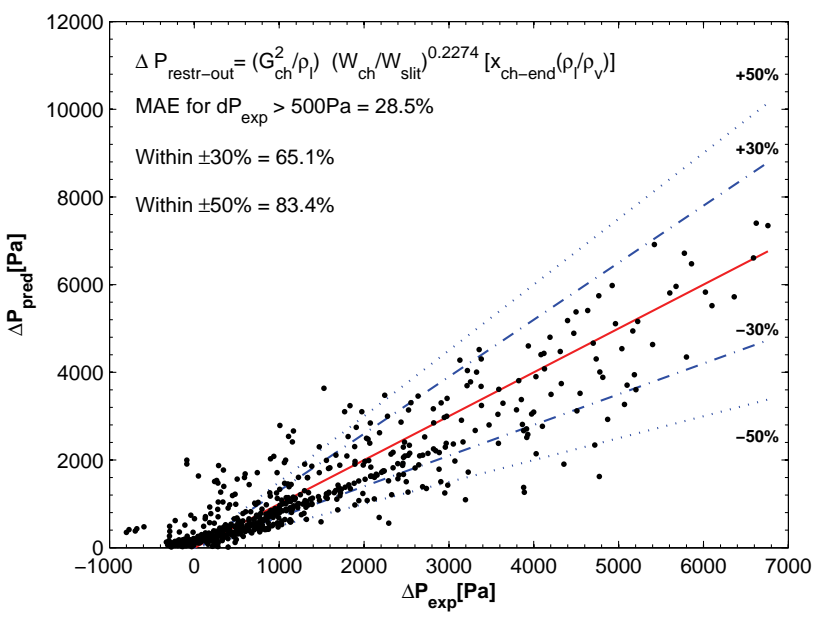

Fig. 5 Comparison between prediction method and experimental results for two-phase outlet restriction pressure drop in multimicrochannels.

Based on equation 16 , to reduce $\Delta p_{\text {restr-out }}$ for a constant mass flow and heat flux without increasing the total pressure drop, this can be achieved two ways:

1. By increasing $\mathrm{W}_{\text {slit }}$ to reduce the ratio of $\mathrm{W}_{c h} / \mathrm{W}_{\text {slit }}$ (decreasing $\mathrm{W}_{c h}$ would increase the channel pressure drop).

2. By using a refrigerant with a low liquid to vapor density ratio, where R-134a and R-1234ze(E) are better choices than R-245fa.

\subsection{Two-phase flow channel pressure drop}

The experiments used to evaluate the microchannel pressure drops were made under a uniform heat flux, varying the mass flux and the saturation temperature. The channel pressure drop was directly measured through $\Delta p_{2}$. An example of the results for the two-phase channel pressure drops for both test sections are shown in Fig 6. The pressure drop increases almost linearly with the quality and with mass flux, trends which are typical of two-phase flows without dry-out. As the vapor quality nears zero, the total pressure drop tends toward the single phase pressure drop of each fluid.

In the case of R-134a and R-1234ze(E), when the channel pressure drop is below $\Delta p_{c h}=6000 \mathrm{~Pa}$, the corresponding saturation temperature drop is less than $0.5^{\circ} \mathrm{C}$. For these two fluids, a constant fluid temperature boundary condition can probably be used for numerical simulations, although the actual values were used for reducing the heat transfer coefficient. In the case of R-245fa, the temperature change from inlet to outlet is around $1^{\circ} \mathrm{C}$

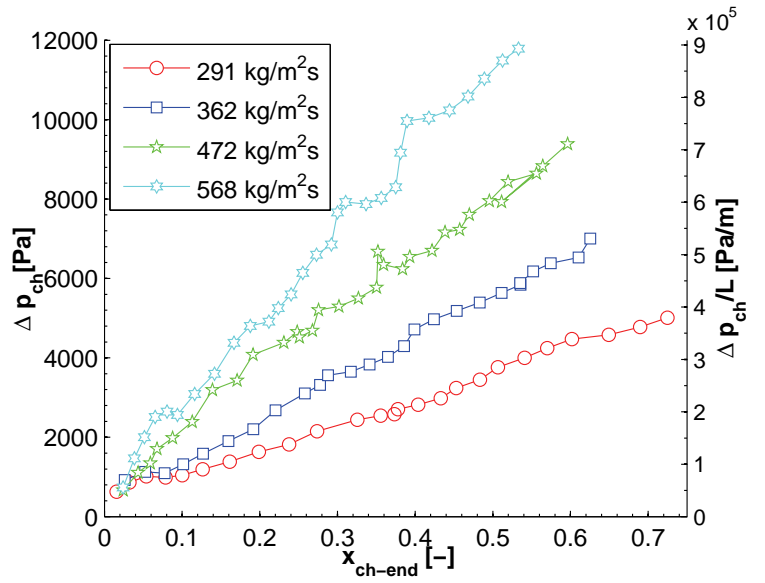

Fig. 6 Channel pressure drop for R-134a at $\mathrm{T}_{\text {sat }}=30.5^{\circ} \mathrm{C}$.

The total pressure drop over the test section is central for the design of efficient cooling systems. If the total pressure drop is very low, a pump-free system such as a thermosyphon could be used to drive the system. In this arrangement, the fluid circulation is induced by a column of liquid. Taking into consideration that in current datacenters, two meter high columns are possible, around $24 \mathrm{kPa}$ would be available to run a pump-free system.

Adding together the results from Figs 3, 4 and 6, it is possible to evaluate the total pressure drop for R-134a. For all mass fluxes, it is possible to maintain that the total micro-evaporator pressure drop parameter below $10 \mathrm{kPa}$, although for $568 \mathrm{~kg} / \mathrm{m}^{2} \mathrm{~s}$, the outlet vapor quality must remain below $\mathrm{x}=0.3$, where $10 \mathrm{kPa}$ corresponds to a liquid column height of less than one meter, well within what is achievable in a datacenter. Therefore, with a careful sizing of the other elements in the cooling systems, it could possible to bring the overal pressure drop of the system below the $20 \mathrm{kPa}$.

Two methods were developed using data derived from rectangular microchannels, those of Lee and Garimella (2008) and

Lee and Mudawar (2005b), although neither had aspect ratios over 3.6. Along with these two correlations, the homogeneous model with Cicchitti et al. (1960)'s viscosity model, the separated flow model of Lockhart and Martinelli (1949) and the methods of

Cioncolini et al. (2009) and Baroczy (1965), adapted by Chisholm (1973) will be compared to the experimental results.

The method of Cioncolini et al. (2009) cannot handle low vapor qualities as it was derived for annular flows only. Thus at low vapor qualities, the method of Lockhart and Martinelli (1949) is used and after the IB-CB transition vapor quality predicted by the map of Ong and Thome (2011a) is reached, the Cioncolini et al. (2009) method is applied. The momentum pressure drop component is included in the comparisons. To calculate it, Zivi (1964)'s void fraction method was be used if the authors did not specify another one. Finally, each method will be evaluated using two different definitions for the hydraulic diameters:

$$
\begin{aligned}
D_{h} & =\frac{4 A}{P}(246 \mu m) \\
D_{h} & =\frac{2 W H}{W+H}(294 \mu m)
\end{aligned}
$$

Table 4 lists the mean absolute error (MAE) obtained for each prediction method with each definition of hydraulic diameter. For each test section, the four best predictions, based on the mean value of MAE for all fluids, are highlighted. The accuracy of some prediction methods can vary a lot depending of the definition of the hydraulic diameter used. Most methods were based on experimental results made using circular 
channels, which poorly describe the shear stress interaction in high aspect ratio channels and applying them to high aspect ratio cross-sections can be problematic.

Table 4 Mean absolute error for prediction of the channel pressure drop.

\begin{tabular}{|c|c|c|c|}
\hline $\mathrm{D}_{h}=246 \mu \mathrm{m}$ & $\mathrm{R} 134 \mathrm{a}$ & $\mathrm{R} 1234 \mathrm{ze}$ & $\mathrm{R} 245 \mathrm{fa}$ \\
\hline Baroczy (1965) & $31.0 \%$ & $20.0 \%$ & $53.0 \%$ \\
Cioncolini et al. (2009) & $50.7 \%$ & $56.1 \%$ & $94.3 \%$ \\
Homogeneous model & $41.0 \%$ & $26.3 \%$ & $149.3 \%$ \\
Lee and Garimella (2008) & $57.8 \%$ & $51.6 \%$ & $42.7 \%$ \\
Lee and Mudawar (2005a) & $\mathbf{3 1 . 8 \%}$ & $\mathbf{3 4 . 2 \%}$ & $\mathbf{3 8 . 6 \%}$ \\
Lockhart and Martinelli (1949) & $\mathbf{4 3 . 2 \%}$ & $\mathbf{3 5 . 7 \%}$ & $\mathbf{2 9 . 2 \%}$ \\
\hline $\mathrm{D}_{h}=294 \mu \mathrm{m}$ & $\mathrm{R} 134 \mathrm{a}$ & $\mathrm{R} 1234 \mathrm{ze}$ & $\mathrm{R} 245 \mathrm{fa}$ \\
\hline Baroczy (1965) & $\mathbf{4 2 . 4 \%}$ & $\mathbf{3 0 . 9 \%}$ & $\mathbf{2 8 . 9 \%}$ \\
Cioncolini et al. (2009) & $\mathbf{3 5 . 0 \%}$ & $\mathbf{3 5 . 7 \%}$ & $\mathbf{3 6 . 3 \%}$ \\
Homogeneous model & $52.2 \%$ & $37.6 \%$ & $86.6 \%$ \\
Lee and Garimella (2008) & $61.8 \%$ & $56.5 \%$ & $45.9 \%$ \\
Lee and Mudawar (2005a) & $42.6 \%$ & $45.0 \%$ & $44.0 \%$ \\
Lockhart and Martinelli (1949) & $53.1 \%$ & $47.7 \%$ & $35.7 \%$ \\
\hline \hline
\end{tabular}

\section{HEAT TRANSFER COEFFICIENT RESULTS}

The 35 temperature sensors provided simultaneous information about the heat transfer over the array heater for each test condition. As a result, the experimental database for heat transfer coefficients under uniform base heat flux is very extensive. Experiments were performed at several mass fluxes, with four refrigerants, at two saturation temperatures and numerous heat fluxes.

\subsection{Validation tests}

Four different validations were done with respect to the local wall heat transfer coefficient results:

- Accuracy with respect to single-phase Nusselt predictions for subcooled liquid tests

- Exactness of the data reduction scheme

- Lateral uniformity of the results

- Repeatability of the results

6.1.1. Single-phase Nusselt number Since copper has a high thermal conductivity, conduction effects are important in the copper test section. Two measures were then taken to counter heat spreading in the copper test section. First, a two-dimensional conduction scheme, presented in Costa-Patry et al. (2011a), was used for the data reduction to include the flow-wise heat spreading. Second, the results from Columns 1 and 7 were not used, because the copper frame dissipated heat flux through the two sides of the evaporator area and measurement zones most affected by this effect were Columns 1 and 7. Both measures (2-D conduction and results from Columns 2 to 6 ) will be applied to the two-phase flow data reduction.

Shah and London (1978) tabulated results for hydrodynamicaly and thermally developing laminar flows. These are expressed in a Taylor series expansion as:

$N u_{z}=3.04+\frac{0.0244}{z^{*}}+\frac{0.448}{\gamma}-\frac{2.69 \times 10^{-5}}{z^{* 2}}+\frac{0.02}{\gamma^{2}}-\frac{6.78 \times 10^{-4}}{z^{*} \gamma}$

where

$$
z^{*}=\frac{\pi}{4} \frac{z}{\operatorname{RePr} D_{h}}
$$

and $\gamma$ is the aspect ratio $\mathrm{W} / \mathrm{H}$. This expression has been compared versus subcooled liquid heat transfer data taken in the test section.

The local and average Nusselt numbers obtained in the test section for R-134a are shown in Fig 7 and compared to the Shah and London (1978) method. The values obtained for $\mathrm{Nu}_{m}$ are well predicted; the mean absolute error for R-134a was $7 \%$. It was possible to reach the transitional flow regime ( $\mathrm{Re} \geq 1200)$ with $\mathrm{R}-134 \mathrm{a}$ and the correlations of Pethukov (1970) for turbulent flow and Olivier (2009) for transitional flow in smooth pipes were used for the comparison. The results for laminar $\mathrm{Nu}_{z}$ are scattered around Shah and London (1978)'s prediction, but once the error bars are taken into account, most datapoint uncertainties cover the predicted values. For R-134a $83 \%$ of the data, including the error bars, fall within $\pm 20 \%$.

The test sections were designed and instrumented for two-phase flow boiling experiments and for low Reynolds number single-phase heat transfer tests, so the instrumentation was not appropriate to measure heat spreading. Thus some single-phase test results will lie outside the predicted values and the validations cannot be performed for all conditions. The importance of heat spreading is greatly reduced in flow boiling as the heat transfer coefficients are ten to thirty-fold higher. Thus, based on the results shown in Fig 7, the single-phase validations show that the instrumentation and the data reduction used for the copper test section are appropriate for two-phase heat transfer coefficients experiments.

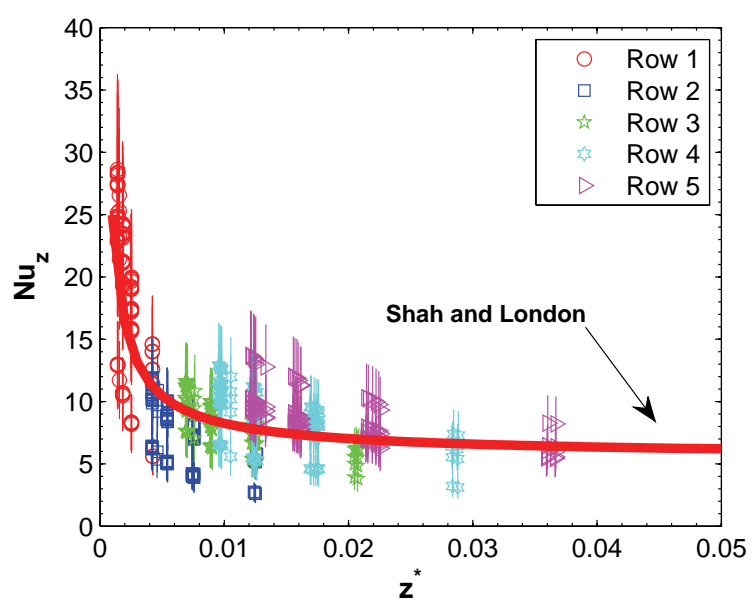

(a) $\mathrm{Nu}_{x}$

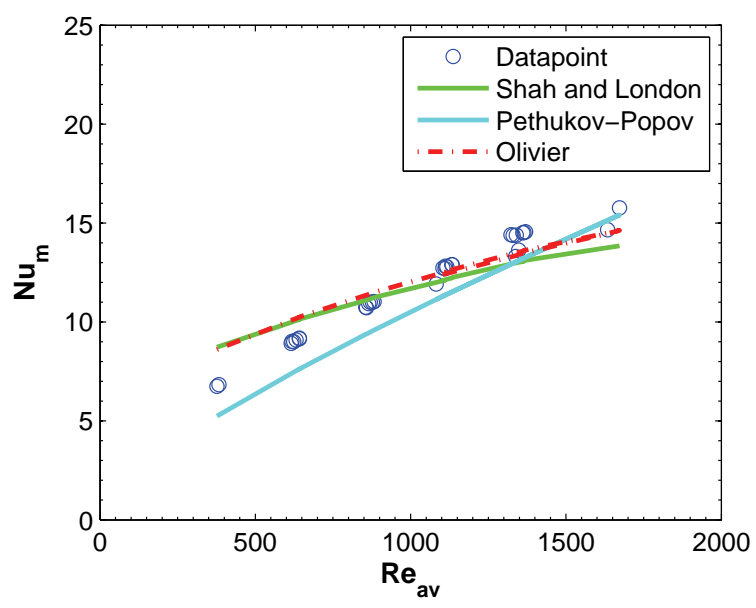

(b) $\mathrm{Nu}_{m}$

Fig. 7 Single-phase validation of the Nusselt number for R-134a 
6.1.2. Thermal conduction data reduction scheme For the data reduction of two-phase flow results, the thermal conduction schemes used in single-phase validations were applied to the experimental measurements. It is important to show that the thermal conduction (heat spreading) was well computed and for this, validations were performed with a numerical simulation program, COMSOL Multiphysics 4.0. This validation is actually a reverse calculation: the results of data reduction are used in the program to set the heat transfer coefficients and then the base temperatures are recalculated. If the results for base temperature agree with the measurements, then the exactness of the data reduction scheme is validated.

In simulations with COMSOL, all boundary conditions must be specified since the program used a different solving strategy than the data reduction scheme. The local heat transfer coefficients calculated through the data reduction were used to create a continuous function from $\mathrm{z}=0$ to $\mathrm{L}_{c h}$ to be input in COMSOL. Comparisons were then made between the measured base temperatures and those calculated by COMSOL using a one-dimensional conduction scheme for the silicon test section and a two-dimensional scheme for the copper test section.

The results of these validations are shown in Fig 8(a) with R-1234ze (E) along with the input "footprint" heat transfer coefficient curve in Fig 8(b). The simulated base temperatures fall very close to the measured values, which means that the heat spreading is well captured by the twodimensional conduction model. Thus, the thermal conduction scheme is accurate and can be used for the calculation of local heat transfer coefficients.

6.1.3. Lateral heat transfer coefficients uniformity To lighten the presentation of the results, the downstream evolution of the local heat transfer coefficients will be presented as a lateral average of the values in all columns as it was done by Costa-Patry et al. (2011b). This is possible because the heat flux and mass flux in each channel are the same, such that in theory the local heat transfer coefficients at any lateral position will also be the same. However in practice, due to small geometrical variations between the channels, there will be differences in heat transfer. These will be more important when the local flow regime is sensitive to the wall geometry, for example for bubble generations and cyclical dry-outs.

In Fig 9, typical lateral profiles of heat transfer coefficients for a given heat flux are plotted. The position of the minimum heat transfer coeffcient moves in the test section. In Columns 2 and 4 it is positioned over Row 3 and in the other columns over Row 4. The differences in trends are probably due to a delay in the flow regime transitions. Since the heat transfer coefficients are not perfectly uniform laterally, the standard deviation will be reported on each graph and noted as the RMS value.

6.1.4. Repeatability of the results An important issue in flow boiling is the repeatability of the tests. The reproductibility of the heat transfer coefficient results are presented in Fig 10 for with R-134a using the lateral mean of the heat transfer coefficients. The different sets of data were recorded with about one month interval between them, referred to as Test 1 and Test 2. In each case, the results for both tests fall on the same trend curve for all heat fluxes. On the graphs, the spread around the trend lines for the Test 1 and 2 pairs (same color) are smaller than the heat transfer coefficient uncertainty and small offsets in vapor quality are observed due to experimentally setting the inlet subcooling. The results were therefore found to be very reproducible both over time and location on the test sections.

\subsection{Two-phase heat transfert coefficients}

The experimental database was obtained for local heat transfer coefficients under uniform base heat flux conditions. The refrigerants were tested at two saturation temperatures, $30^{\circ} \mathrm{C}$ and $50^{\circ} \mathrm{C}$ and at mass fluxes from 205 to $569 \mathrm{~kg} / \mathrm{m}^{2} \mathrm{~s}$. The base heat flux was incrementally raised until the base temperature reached $85^{\circ} \mathrm{C}$. Base heat fluxes varied from 130 to $2950 \mathrm{~kW} / \mathrm{m}^{2}$ (13 to $295 \mathrm{~W} / \mathrm{cm}^{2}$ ). No attempt was made to reach the

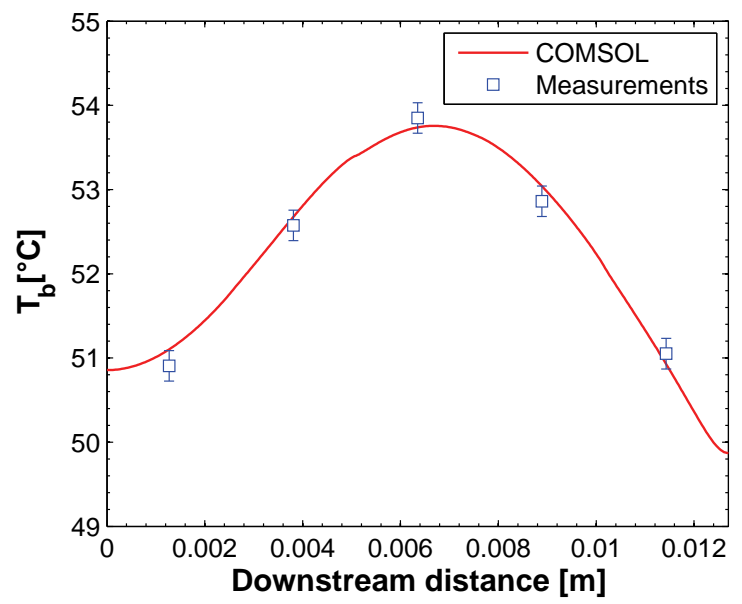

(a) Base temperature

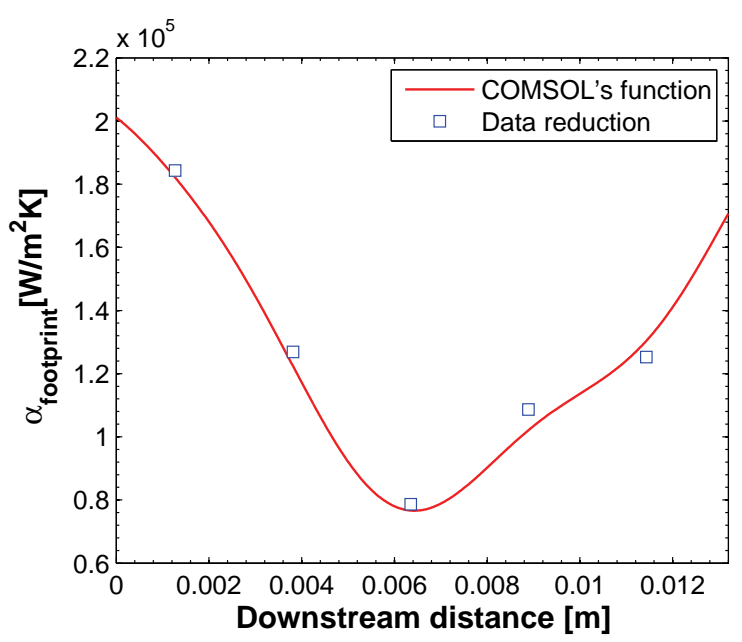

(b) Footprint heat transfer coefficients

Fig. 8 Comparison between the two-dimensional thermal conduction data reduction and COMSOL Multiphysics' results for the copper test section: R-1234ze(E), $411 \mathrm{~kg} / \mathrm{m}^{2} \mathrm{~s}$, Column $6, \mathrm{q}_{b}=136.3 \mathrm{~W} / \mathrm{cm}^{2}$.

critical heat flux to prolong the life of the test sections.

In order to report the results in a consistent fashion, the wall heat transfer coefficients are analyzed only with respect to the wall heat flux, accounting of course for the fin efficiency of the walls. For quick comparisons, multiplying the wall heat flux and heat transfer coefficients by 8 yields a value close to the equivalent "footprint area" heat transfer coefficient. Eight is the rounded value of the right hand side coefficient multiplying $\mathrm{q}_{\text {footprint, xy }}$ in equation 11 .

A representative sample to the results for average wall heat transfer coefficients versus vapor quality are shown in Figs 11 to 13. On the graphs, each curve is composed of five measurement points, corresponding to each row position. The points are linked by a cubic spline to help the visualization of trends. This curve fit should not be used to infer the local heat transfer coefficients between the measurement points. The wall heat transfer coefficients were calculated using the local wall heat flux values. However each curve is described by the average value of wall heat flux for that test condition. Due to the local change in fin efficiency and heat spreading, there are differences between this average value and the local ones. These can represent up to $\pm 15 \%$ of the mean value, but is usually closer to $\pm 7 \%$. Error bars are not shown in order to make the graphs readible. Note that the uncertainty on the heat transfer value typically decreases with increasing heat flux, since the temperature 


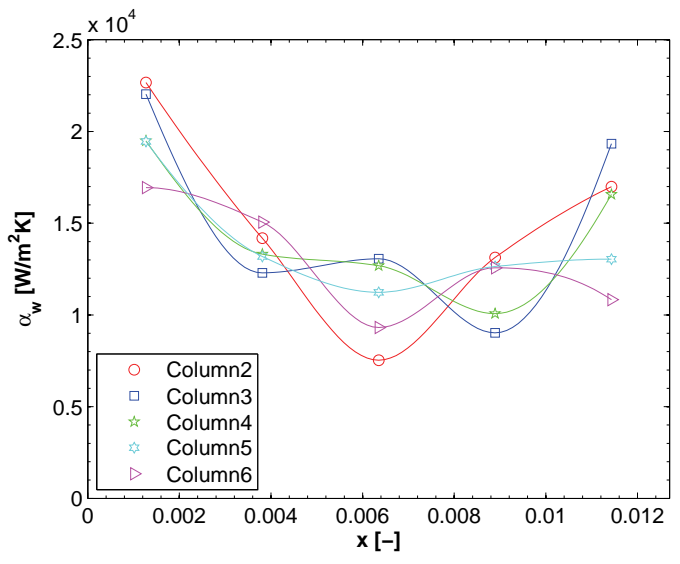

Fig. 9 Heat transfer coefficients in all columns. R-134a, $473 \mathrm{~kg} / \mathrm{m}^{2} \mathrm{~s}$, $\mathrm{q}_{b}=1290 \mathrm{~kW} / \mathrm{m}^{2}, \mathrm{~T}_{\text {sat }}=50.7^{\circ} \mathrm{C}$.

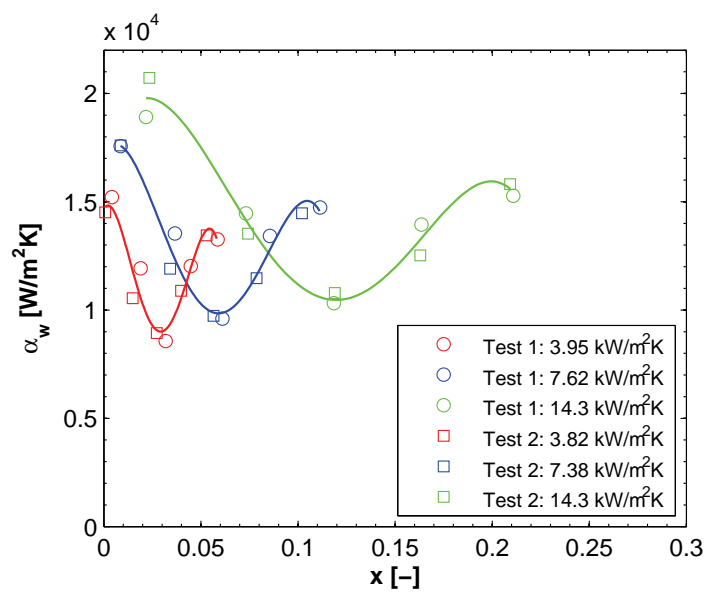

Fig. 10 Reproductibility of $\alpha_{w}$ at different wall heat fluxes. R-134a, $411 \mathrm{~kg} / \mathrm{m}^{2} \mathrm{~s}$.

difference between the fluid and the wall increases.

The peak heat transfer is positioned at Row 1 and increases with heat flux. The highest wall heat transfer coefficient measured is $27^{\prime} 000$ $\mathrm{W} / \mathrm{m}^{2} \mathrm{~K}$ with R-134a at $403 \mathrm{~kW} / \mathrm{m}^{2}$ for a mass flux of $568 \mathrm{~kg} / \mathrm{m}^{2} \mathrm{~s}$ and at a saturation temperature of $29.9^{\circ} \mathrm{C}$ (as a "footprint" heat transfer coefficient this is a value of about $216^{\prime} 000 \mathrm{~W} / \mathrm{m}^{2} \mathrm{~K}$ ). In most cases, the heat transfer increases at the end of the curve and the minimum is positioned over Row 3 or 4 . As the vapor quality increases, the influence of heat flux decreases and the heat transfer coefficients tend toward a common curve, as was seen in the silicon test section and by Ong and Thome (2011b) in single channel tests. The higher saturation temperature does not significantly change the heat transfer trends, although the heat transfer levels are slightly higher at higher temperature. For example, in Figs 12(b) and 12 (c), the heat transfer values at $170 \mathrm{~kW} / \mathrm{m}^{2}$ are on average $1260 \mathrm{~W} / \mathrm{m}^{2} \mathrm{~K}$ higher at $50.9^{\circ} \mathrm{C}$ than at $30.2^{\circ} \mathrm{C}$ (about 5 to $10 \%$ ).

At $160 \mathrm{~kW} / \mathrm{m}^{2}$ and at about $350 \mathrm{~kg} / \mathrm{m}^{2} \mathrm{~s}$, Fig 14 compares the heat transfer coefficients for all fluids at similar test conditions. For this case the highest heat transfer coefficients are obtained with R-1234ze(E) and that all three fluids follow the same general trend. The wall heat transfer coefficients were replotted for R-134a and R-1234ze(E) at constant heat flux and varying mass fluxes in Figs 15 and 16. At low vapor quality, the heat transfer coefficient is higher for low mass fluxes. Otherwise in Fig 15(b), the mass flux has little influence on the increasing branch. When the heat flux is higher, as in Figs 15(a), 16 and 17, the curves are separated at high vapor quality with lower heat transfer at low mass fluxes. This again supports the possibility that cyclical dry-outs are occurring. Since those dry-outs are not permanent, they do not lead to critical heat flux, but once time-averaged, they decrease the local heat transfer coefficient.

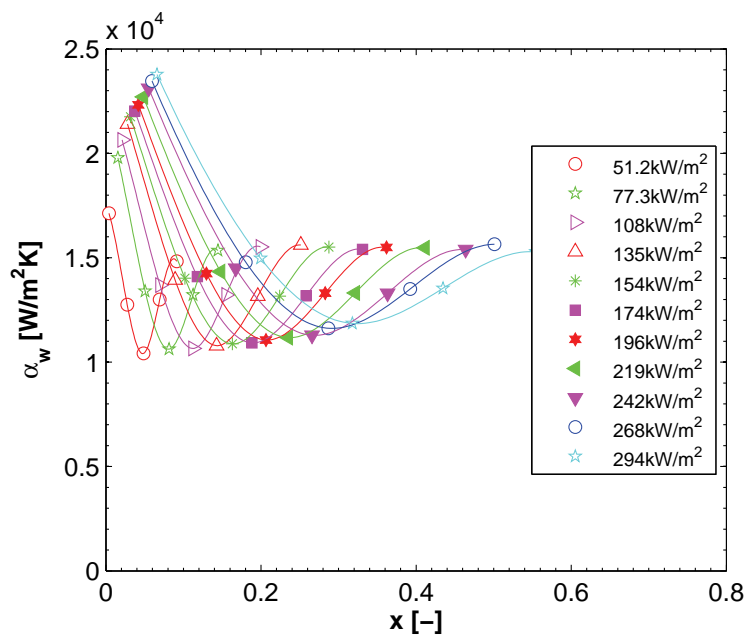

(a) $367 \mathrm{~kg} / \mathrm{m}^{2} \mathrm{~s}, \mathrm{~T}_{\text {sat }}: 30.6^{\circ} \mathrm{C}$, Error: $4.8 \%$, RMS: $13.3 \%$

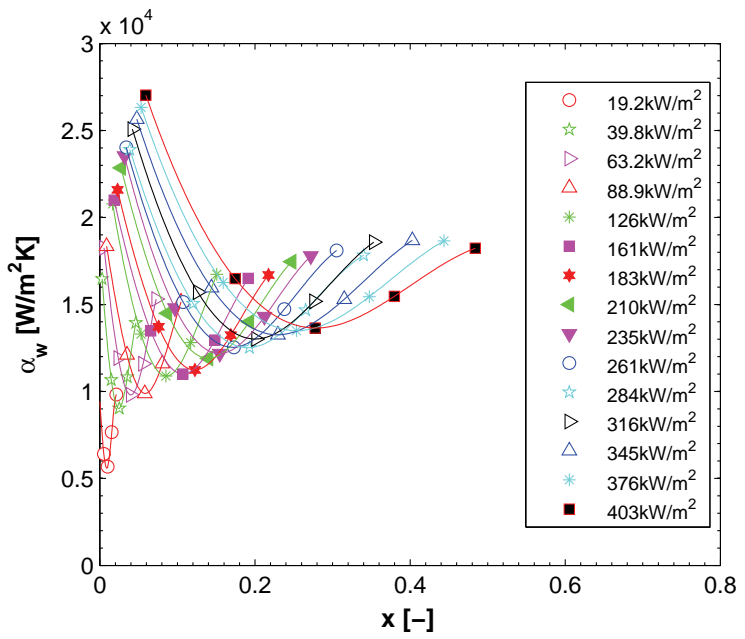

(b) $568 \mathrm{~kg} / \mathrm{m}^{2} \mathrm{~s}, \mathrm{~T}_{\text {sat }}: 29.9^{\circ} \mathrm{C}$, Error: $5.4 \%$, RMS: $12.9 \%$

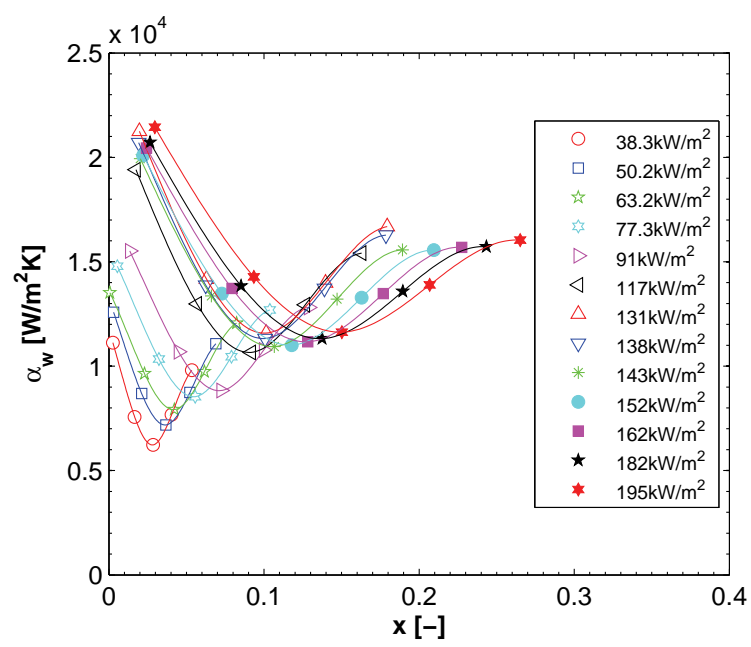

(c) $570 \mathrm{~kg} / \mathrm{m}^{2} \mathrm{~s}, \mathrm{~T}_{\text {sat }}: 50.7^{\circ} \mathrm{C}$, Error: $7.9 \%$, RMS: $14.8 \%$

Fig. $11 \alpha_{w}$ for R-134a at different $\mathrm{q}_{w}$. 


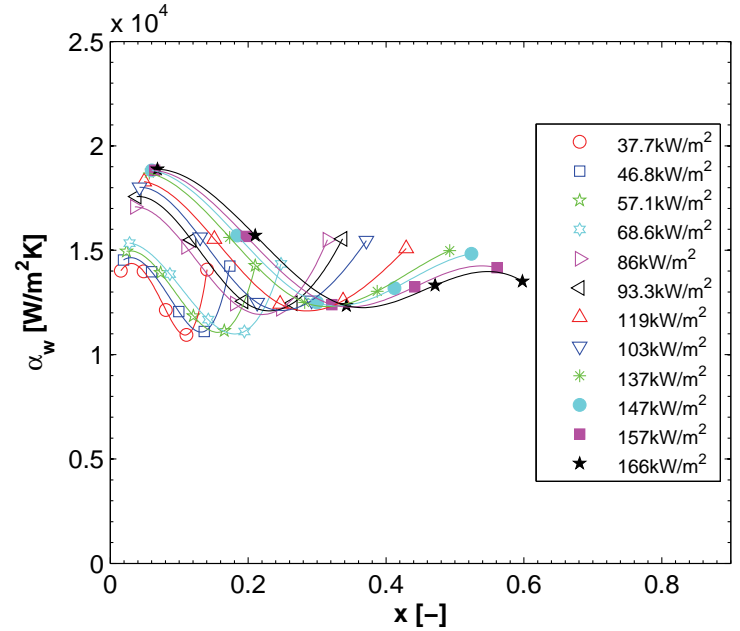

(a) $205 \mathrm{~kg} / \mathrm{m}^{2} \mathrm{~s}, \mathrm{~T}_{\text {sat }}: 30.6^{\circ} \mathrm{C}$, Error: $4.8 \%$, RMS: $13.3 \%$

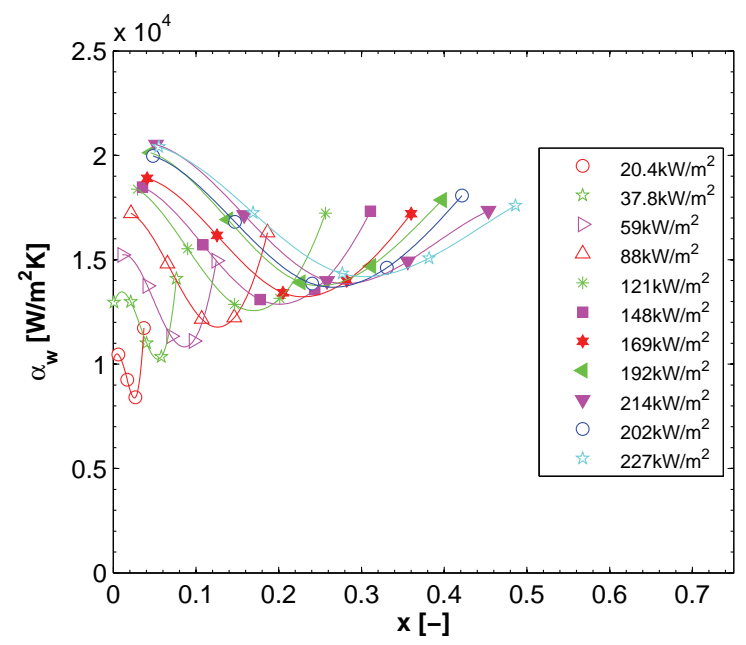

(b) $342 \mathrm{~kg} / \mathrm{m}^{2} \mathrm{~s}, \mathrm{~T}_{\text {sat }}: 29.9^{\circ} \mathrm{C}$, Error: $5.4 \%$, RMS: $12.9 \%$

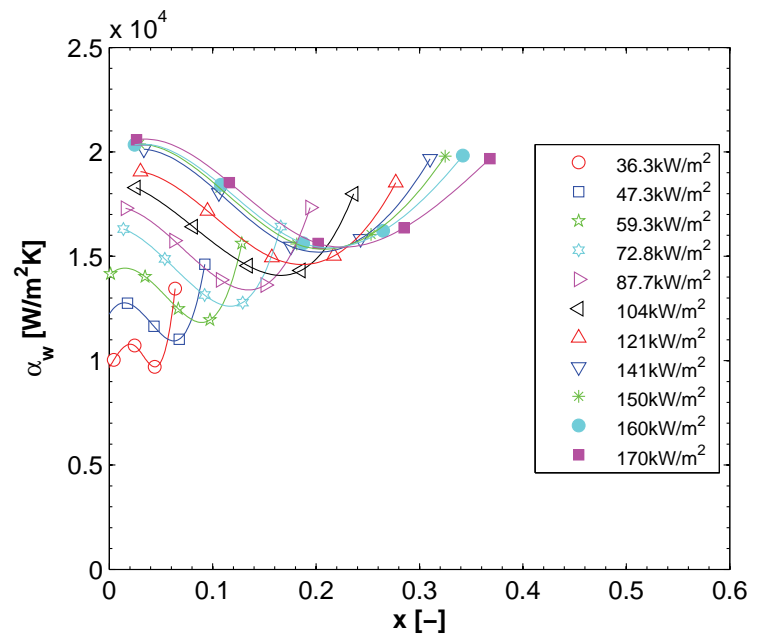

(c) $351 \mathrm{~kg} / \mathrm{m}^{2} \mathrm{~s}, \mathrm{~T}_{\text {sat }}: 50.7^{\circ} \mathrm{C}$, Error: $7.9 \%$, RMS: $14.8 \%$

Fig. $12 \alpha_{w}$ for R-1234ze(E) at different $\mathrm{q}_{w}$.

\section{FLOW PATTERN-BASED PREDICTION METHOD}

A new flow pattern-based method is proposed below using the threezone model of Thome et al. (2004) for the intermittent flow regime and the model of Cioncolini and Thome (2011) for the annular flow region

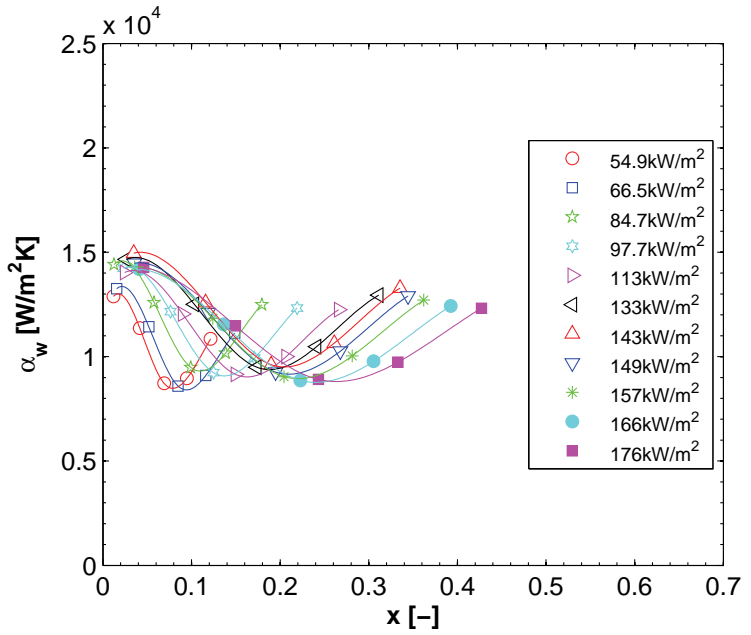

(a) $290 \mathrm{~kg} / \mathrm{m}^{2} \mathrm{~s}, \mathrm{~T}_{\text {sat }}: 30.6^{\circ} \mathrm{C}$, Error: $7.2 \%$, RMS: $17.4 \%$

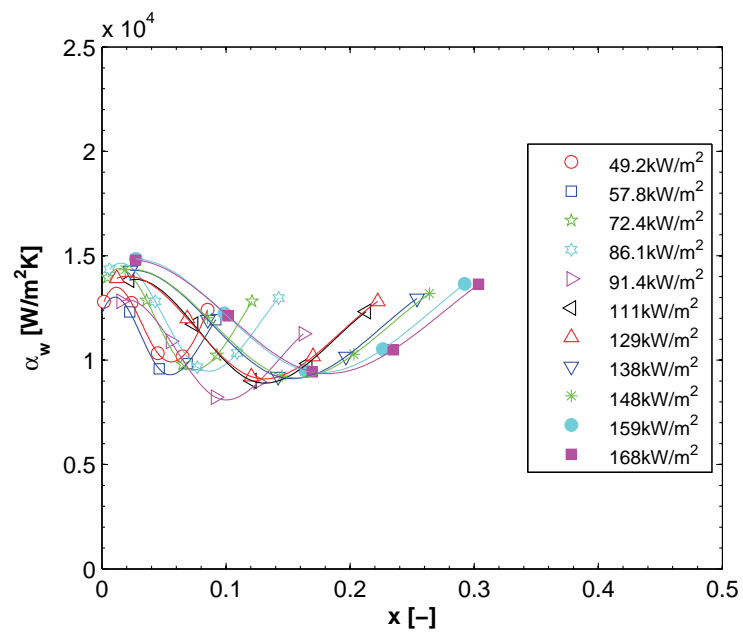

(b) $365 \mathrm{~kg} / \mathrm{m}^{2} \mathrm{~s}, \mathrm{~T}_{\text {sat }}: 29.9^{\circ} \mathrm{C}$, Error: $8.5 \%$, RMS: $15.8 \%$

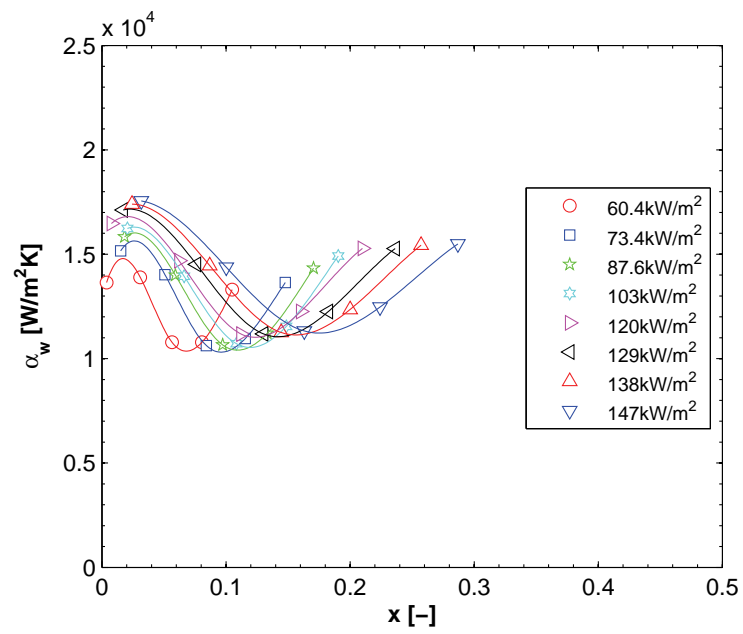

(c) $366 \mathrm{~kg} / \mathrm{m}^{2} \mathrm{~s}, \mathrm{~T}_{\text {sat }}: 50.7^{\circ} \mathrm{C}$, Error: $6.8 \%$, RMS: $16.0 \%$

Fig. $13 \alpha_{w}$ for R-245fa at different $\mathbf{q}_{w}$.

(AF). The intermittent flow regime combines the IB (isolated bubble flow regime) and $\mathrm{CB}$ (coalescing bubble flow regime) flow regimes into one. Both methods were modified to fit better the high-aspect ratio microchannel and a new flow pattern transition criteria is proposed based on the experimental results. 


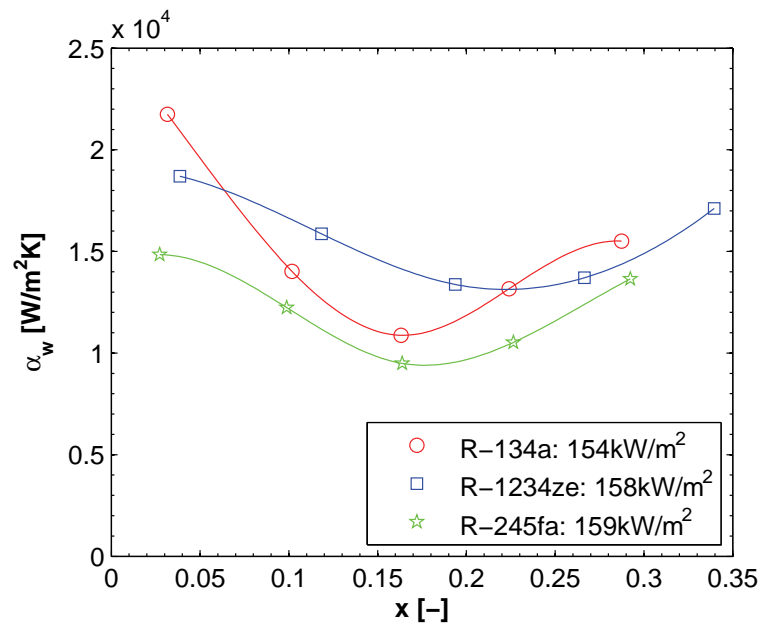

Fig. 14 Comparison between R-134a, R-1234ze(E) and R-245fa around $350 \mathrm{~kg} / \mathrm{m}^{2} \mathrm{~s}$ and $\mathrm{T}_{\text {sat }}=30^{\circ} \mathrm{C}$.

\subsection{Transition criteria}

Comparing wall heat transfer coefficient results with flow pattern maps, Ong and Thome (2011a) predicts a IB-CB transition to be at around $\mathrm{x}=$ 0.05 and $\mathrm{a} \mathrm{CB}-\mathrm{AF}$ transition at around $\mathrm{x}=0.15$ for both test sections. The influence of the IB-CB transition is not seen in the heat transfer results, although the cubic spline can give this impression in some graphs. On the other hand, the $\mathrm{CB}-\mathrm{AF}$ transition vapor quality is sometimes close the position of the minimum heat transfer coefficients, although the predicted transition vapor quality does not change with heat flux.

The $\mathrm{CB}-\mathrm{AF}$ transition should influence the heat transfer level. In the coalescing bubble flow regime, the heat transfer should drop, because depending on the model, the importance of dry-out increases (three-zone, Thome et al. (2004)) or the importance of nucleate boiling, which has an higher rate of heat removal, decreases (Bertsch et al. (2009)). In the annular flow regime, heat transfer is a function of the liquid film thickness. When the vapor quality increases, the film becomes thinner and the heat transfer coefficient increases.

In this case, the inflection point in the heat transfer coefficient curves should denote a change in flow pattern and thus can be used to track the diabatic CB-AF transition. This was done in Fig 18 for R-134a in the copper test section. The vapor quality where the minimum heat transfer occurs increases with increasing heat flux and to a lesser degree with a decreasing mass flux. Tracking the minimum on the wall heat transfer coefficients graphs, a new transition criteria can be defined to include the effect of heat flux in the Ong and Thome (2011a) map for the CB-AF transition and was also plotted in Fig 18.

Three differerent databases were used to determine the transition vapor quality: the current one, the database of Costa-Patry et al. (2011b) obtained using a silicon evaporator and the extensive database for three circular tubes $(\mathrm{D}=1.03 \mathrm{~mm}, 2.20 \mathrm{~mm}$ and $3.04 \mathrm{~mm})$ presented in

Ong and Thome (2011b). Together these studies form a database covering diabatic conditions with wall heat fluxes from $8 \mathrm{~kW} / \mathrm{m}^{2}$ to $260 \mathrm{~kW} / \mathrm{m}^{2}$, mass fluxes from $100 \mathrm{~kg} / \mathrm{m}^{2} \mathrm{~s}$ to $1100 \mathrm{~kg} / \mathrm{m}^{2} \mathrm{~s}$, four different refrigerants, for hydraulic diameters from $146 \mu \mathrm{m}$ to $3.04 \mathrm{~mm}$. Based on the studies, the vapor qualities at which the minimum heat transfer coefficients occur were found to be well predicted by

$$
x_{C B-A F}=425\left(\frac{\rho_{v}}{\rho_{l}}\right)^{0.1} \frac{B o^{1.1}}{C o^{0.5}}
$$

where Bo is the boiling number and Co the confinement number. The constants were found by a least fit square iteration. Equation 21 says that the transition is a function of the liquid to vapor density ratio, of

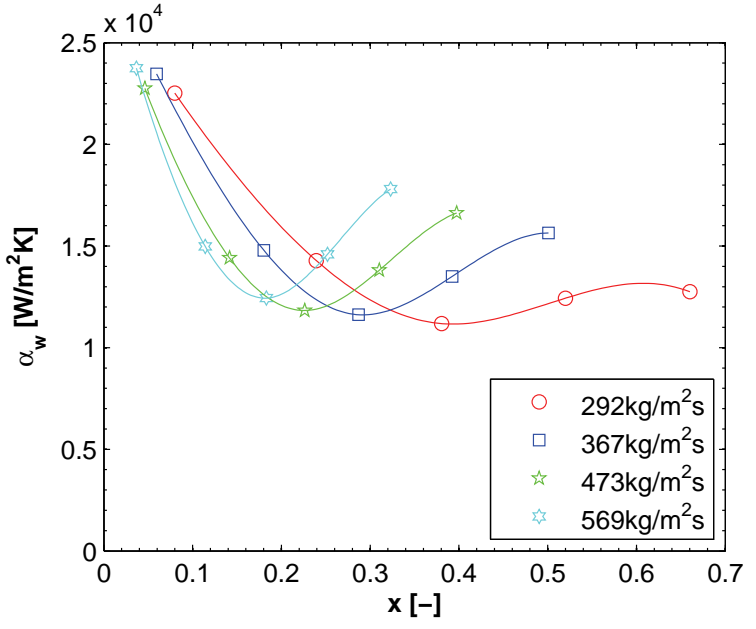

(a) $\mathrm{T}_{\text {sat }}: 31^{\circ} \mathrm{C}, \mathrm{q}_{w}=270 \mathrm{~kW} / \mathrm{m}^{2}$

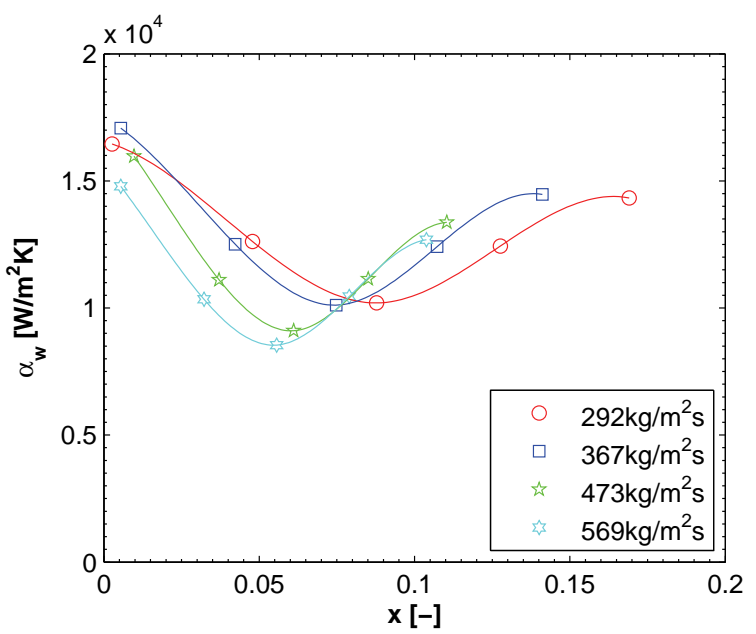

(b) $\mathrm{T}_{\text {sat }}: 51^{\circ} \mathrm{C}, \mathrm{q}_{w}=72 \mathrm{~kW} / \mathrm{m}^{2}$

Fig. $15 \alpha_{w}$ for R-134a for increasing mass fluxes.

the diameter through the confinement number and finally of the heat flux and the mass flux, both contained in the boiling number. In the database, the minima found at the first and last measurement point were excluded, because in the first case, they were due to a subcooling effect and in the second case, it is not possible to say if the minimum has been reached.

More than $95 \%$ of the minimum data fall within the experimental resolution. Points falling within the experimental resolution were counted as accurate, where the resolution is defined as the difference in vapor quality between two measurement points. For example, if at Row $3 \mathrm{x}$ is 0.3 and at Row $4 \times$ is 0.4 , the resolution is 0.1 .

Although the number of mass fluxes tested is small, the shape of the transition curves in Fig 18 is reminiscent of that of Ong and Thome (2011a). However the boiling number is absent from their correlations. Their observations were made in a adiabatic glass tube placed after an heated section of tube stainless steel tube. Differences in the test setup could explain why they did not find an effect of the heat flux on the CB$\mathrm{AF}$ transition. Thus, it is recommended here to use the Ong and Thome (2011a) map with the new CB-AF transition proposed here.

\subsection{Modification to the heat transfer prediction methods}

7.2.1. Three-zone model The three-zone model used for the flow pattern based model differs from the original publication. First, as shown by several authors (Agostini et al. (2008) and Ong and Thome (2011b)), the three-zone model works better when the minimum film thickness was 


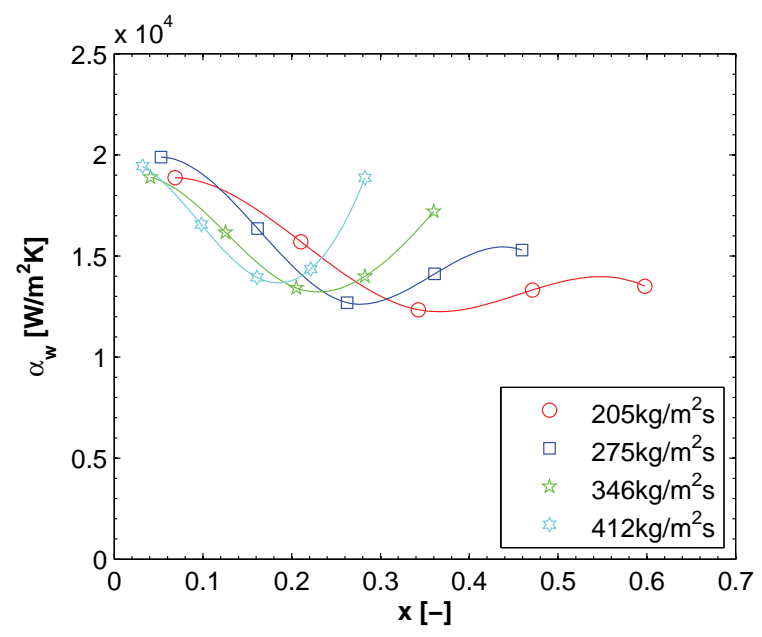

(a) $\mathrm{T}_{\text {sat }}: 31^{\circ} \mathrm{C}, \mathrm{q}_{w}=165 \mathrm{~kW} / \mathrm{m}^{2}$

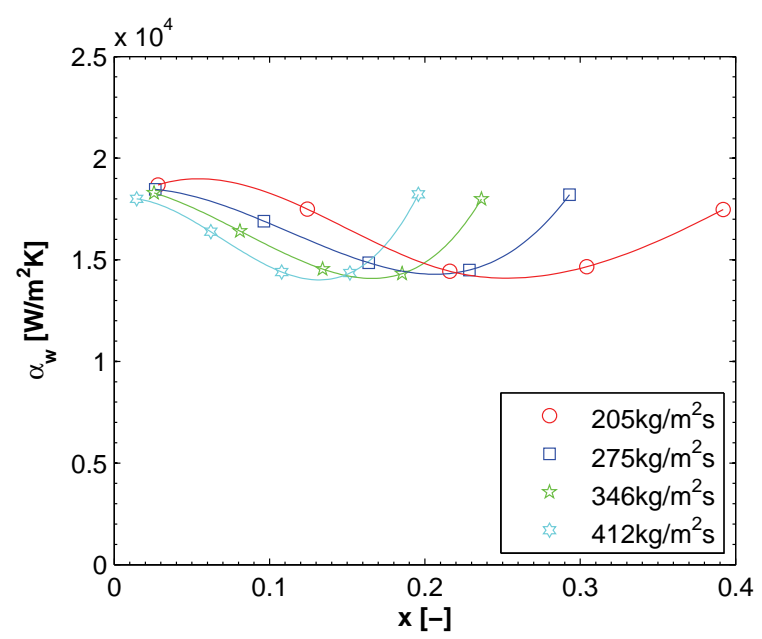

(b) $\mathrm{T}_{\text {sat }}: 51^{\circ} \mathrm{C}, \mathrm{q}_{w}=100 \mathrm{~kW} / \mathrm{m}^{2}$

Fig. $16 \alpha_{w}$ for R-1234ze(E) for increasing mass fluxes.

set to the wall roughness. Second, the correlations used in the Nusselt number calculations for the liquid and vapor slugs were changed. The developing flow equations, which could lead to non-sensical results in small channels, were replaced by fully-developed ones as follows:

$$
\begin{gathered}
N u_{\text {lam }}=4.36 \\
N u_{\text {turb }}=\frac{\operatorname{Pr} \frac{f}{8}(\operatorname{Re}-1000)}{1+12.7\left(\frac{f}{8}\right)^{0.5}\left(\operatorname{Pr}^{2 / 3}-1\right)}
\end{gathered}
$$

for $\operatorname{Re} \geq 1500$.

Finally, the original definition of the liquid film heat transfer was used. To prevent the computational problems observed by Dupont et al. (2004) when $\delta_{0} \approx \delta_{\text {end }}$, the denominator was stabilized by adding one nanometer in the substraction such that:

$$
h_{f i l m}=\frac{\lambda_{l}}{\delta_{o}-\delta_{\text {end }}+1 \times 10^{-9}} \ln \frac{\delta_{o}}{\delta_{\text {end }}}
$$

7.2.2. Annular flow model The Cioncolini and Thome (2011) annular flow method needs to be adapted to use it for non-circular shapes. It balances forces in the channel to calculate a radial film thickness in a circular channel. This film must be redistributed to the rectangular perimeter keeping the same area proportion between the shapes and to conserve the

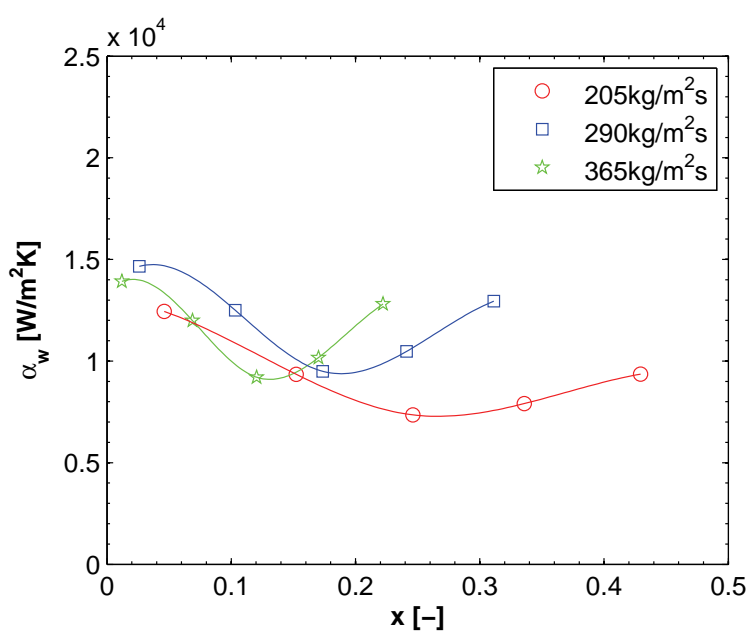

Fig. $17 \alpha_{w}$ for R-245fa for increasing mass fluxes and $\mathrm{q}_{w}=130 \mathrm{~kW} / \mathrm{m}^{2}$ at $\mathrm{T}_{\text {sat }}=31.0^{\circ} \mathrm{C}$.

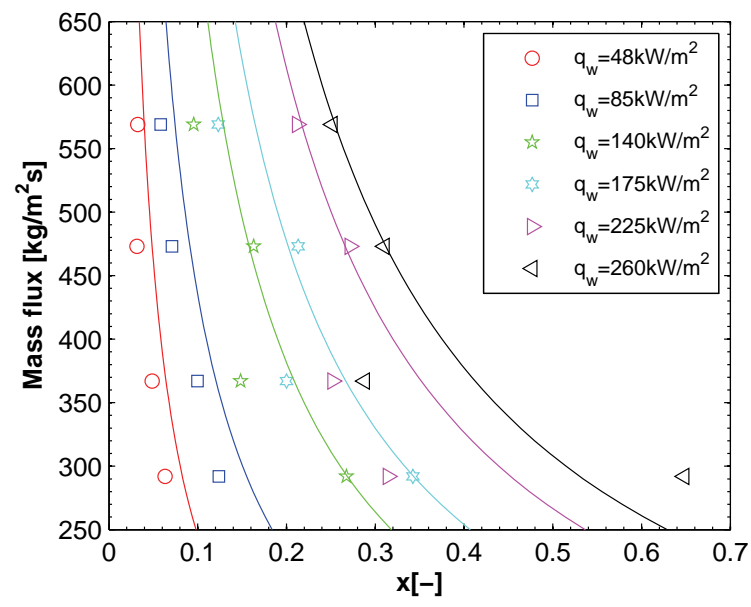

Fig. 18 Vapor quality at the minimum heat transfer coefficients for R134 a in copper test section

liquid cross-sectional area proportions, so it make sense to use the equivalent diameter, $\mathrm{D}_{h}=\sqrt{\frac{4 W H}{\pi}}$ for this method. Note that in the model, the true value of the perimeter was used and not $2(\mathrm{~W}+\mathrm{H})$. As a consequence of this adaptation, the average rectangular film thickness was about half the circular one.

In practice, the liquid film thickness is first calculated for the equivalent circular pipe. Then the cross-sectional area taken by the circular film is calculated $\left(A=\frac{\pi}{4}\left(D_{h}^{2}-\left(D_{h}-2 \delta\right)^{2}\right)\right)$. The liquid film must occupy the same area in the rectangular shape as in the circular pipe. In such case, the liquid film thickness in the rectangular liquid film thickness is found by dividing the liquid film area by the rectangular channel perimeter ( $\delta=A /$ Perimeter $)$. The Nusselt number calculated by the method is finally transformed in an heat transfer coefficient by dividing it by the rectangular liquid film thickness.

\subsection{Description and accuracy}

The two methods were here combined to form the first flow-pattern based prediction method for flow boiling in microchannels with a smooth transition in the heat transfer coefficient created by the inclusion of a "buffer" zone, since the three-zone $\left(\alpha_{3 Z}\right)$ and annular $\left(\alpha_{A F}\right)$ do not match in value at the $\mathrm{CB}-\mathrm{AF}$ transition. All data below the $\mathrm{CB}-\mathrm{AF}$ transition zone were treated by the three-zone model (i.e. IB and CB flow regimes). For mea- 
surement points with a vapor quality in the transition zone, the heat transfer was a combination of the three-zone and the annular flow models. Finally, for measurements at vapor qualities higher than the transition zone, the annular flow model was used.

The vapor quality transition zone was defined based on the experimental resolution to be from:

$$
x_{C B-A F} \pm \frac{x_{\text {exit }}}{5}
$$

The term, $\mathrm{x}_{\text {exit }}$ is evaluated from an energy balanced from inlet to outlet of the evaporator, neglecting the effect of flashing due to the pressure losses. Entering the transition zone, the heat transfer coefficient should be equal to the three-zone value and exiting it, it should be equal to the annular flow value. The proration factor $r$ within the zone is:

$$
r=\frac{x-x_{C B-A F}}{0.2 x_{\text {exit }}}+0.5
$$

At $r=0.5$ (the minimum), the heat transfer coefficient should be a balance between both models, such that if $\alpha_{3 Z}$ is small, $\alpha_{A F}$ dominates and vice versa. Bringing both considerations together, the equation for the heat transfer coefficient in the transition zone is:

$$
\begin{aligned}
\alpha_{C B-A F}=( & 1-r) \alpha_{3 Z}+\frac{r \alpha_{A F}}{(1-r) \alpha_{3 Z}+r \alpha_{A F}} \\
& \times\left(r \alpha_{A F}-(1-r) \alpha_{3 Z}\right)
\end{aligned}
$$

The heat transfer coefficient results for uniform heat flux from the current experimental database, that presented by Costa-Patry et al. (2011b) for a silicon micro-evaporator and the circular pipes database of Ong and Thome (2011b) were be compared with four prediction methods, namely:

1. New flow pattern-based mode

2. Bertsch et al. (2009)

3. Lee and Mudawar (2005b)

\section{Tran et al. (1996)}

As given in Tables 5, 6 and 7, the new method is as good as that of Bertsch et al. (2009) for the copper test section and the circular pipes, and is $10 \%$ more accurate than any other method in the silicon test section. For the copper test section and the circular pipes, the mean absolute error for all fluids are respectively $27.9 \%$ and $27.8 \%$. For the silicon test section, the mean absolute error decreases to $19.4 \%$. Note that for the circular pipes, the method of Tran et al. (1996) is the most accurate, however it is not accurate for the other test sections.

Table 5 Mean absolute error for local heat tranfer coefficients in the silicon test section. Data from Costa-Patry et al. (2011b)

\begin{tabular}{|c|c|c|c|}
\hline Silicon test section & R236fa & R245fa & All \\
\hline New method & $\mathbf{1 7 . 3 \%}$ & $\mathbf{2 1 . 9 \%}$ & $\mathbf{1 9 . 4 \%}$ \\
Bertsch et al. (2009) & $23.3 \%$ & $37.1 \%$ & $29.5 \%$ \\
Lee \& Mud. (2005b) & $48.8 \%$ & $60.6 \%$ & $54.1 \%$ \\
Tran et al. (1996) & $62.4 \%$ & $82.1 \%$ & $71.2 \%$ \\
\hline
\end{tabular}

Fig 19 shows simulations of the new model and that of Bertsch et al. (2009) at the same conditions as in Fig 11(c) for R-134a. The new model reproduced the heat transfer trends much better than the method of Bertsch et al. (2009). The minimum in the test data are seen to be reproduced well by the new flow pattern based model while not by the other method. The method predicts a V-shape profile similar to the experiments, although it underestimates the slope of the second branch and overestimates slightly the heat transfer values at the inlet, which typically fall in the IB flow regime. Getting the correct trends is very important when evaluating the local temperature in the eventual CPU being cooled.
Table 6 Mean absolute error for the local heat tranfer coefficients in the copper test section.

\begin{tabular}{|c|c|c|c|c|}
\hline Copper test section & R134a & R1234ze & R245fa & All \\
\hline New method & $\mathbf{2 1 . 9 \%}$ & $\mathbf{3 3 . 1 \%}$ & $\mathbf{3 2 . 9 \%}$ & $\mathbf{2 7 . 9 \%}$ \\
Bertsch et al. (2009) & $\mathbf{2 9 . 3 \%}$ & $\mathbf{2 3 . 3 \%}$ & $\mathbf{3 0 . 9 \%}$ & $\mathbf{2 7 . 4 \%}$ \\
Lee \& Mud. (2005b) & $36.2 \%$ & $38.8 \%$ & $24 \%$ & $35.4 \%$ \\
Tran et al. (1996) & $30.5 \%$ & $48.5 \%$ & $72.0 \%$ & $42.4 \%$ \\
\hline
\end{tabular}

Table 7 Mean absolute error for the local heat tranfer coefficients in stainless steel circular tubee. Data from Ong and Thome (2011b)

\begin{tabular}{|c|c|c|c|c|}
\hline Circular tubes & $1.03 \mathrm{~mm}$ & $2.20 \mathrm{~mm}$ & $3.04 \mathrm{~mm}$ & All \\
\hline New method & $26 \%$ & $32.6 \%$ & $24.7 \%$ & $27.8 \%$ \\
Bertsch et al. (2009) & $19.6 \%$ & $26.3 \%$ & $30.2 \%$ & $25.4 \%$ \\
Lee \& Mud. (2005b) & $51.9 \%$ & $72 \%$ & $78.5 \%$ & $67.5 \%$ \\
Tran et al. (1996) & $\mathbf{2 5 . 5 \%}$ & $\mathbf{1 6 . 5 \%}$ & $\mathbf{1 5 . 3 \%}$ & $\mathbf{1 9 . 1 \%}$ \\
\hline
\end{tabular}

\section{CONCLUSIONS}

The pressure drop and heat transfer characteristics of flow boiling of R-134a, R-1234ze(E) and R-245fa were investigated in a copper multimicrochannel evaporator. The experimental instrumentation was designed to be able to measure the outlet restriction pressure drop. Using the results from two test sections, a prediction method for the outlet restriction pressure drop was developed starting from the equation for pressure drop across a sudden expansion from Collier and Thome (1994). Adding each pressure drop component, the total pressure drop in the copper test section was found to be low enough to be driven by a pump-free system, such as a thermosyphon.

Heat transfer coefficients for uniform heat flux conditions were tested for wall heat fluxes varying from 15 to $400 \mathrm{~kW} / \mathrm{m}^{2}$ and were found to be as high as $27^{\prime} 000 \mathrm{~W} / \mathrm{m}^{2} \mathrm{~K}$. For a given heat flux, they typically followed a $\mathrm{V}$-shape as the vapor qualities increased. Each branch was associated to a flow pattern: intermittent flow and annular flow. The minimum point in the V-shape trend was used to develop an heat flux dependent transition criteria between intermittent and annular flow. Using this criteria, it was then possible to develop the first flow pattern-based prediction method for flow boiling heat transfer coefficients in microchannels. The resulting method was found to give the most precise predictions and followed very well the experimental trends.

\section{ACKNOWLEDGEMENTS}

The authors thank the Swiss Federal Office for Professional Education and Technology (KTI) for sponsoring this work under contract No. 6862.2 DCS-NM. The authors also wish to recognize the support of Stephan Paredes of IBM Research Zürich and Yassir Madhour (LTCM laboratory) for the fabrication of the test section and the financial contributions of IBM and Embraco towards this project. Furthermore, the authors thank Wolverince Tube Inc. for manufacturing the copper micro-evaporator and Honeywell International for providing the R-1234ze(E).

\section{NOMENCLATURE}

$\begin{array}{ll}A & \text { Area }\left(\mathrm{m}^{2}\right) \\ A F & \text { Annular flow regime } \\ B & \text { Evaporator width }(\mathrm{m}) \\ B o & \text { Boiling number }\left(\frac{q}{G h_{l v}}\right) \\ C B & \text { Coaslescing bubble flow regime } \\ C o & \text { Confinement number }\left(\frac{1}{D_{h}} \sqrt{\frac{\sigma}{g\left(\rho_{l}-\rho_{v}\right)}}\right) \\ c & \text { Heat capacity }(\mathrm{kJ} / \mathrm{kgK}) \\ D_{h} & \text { Hydraulic diameter }(\mathrm{m})\end{array}$




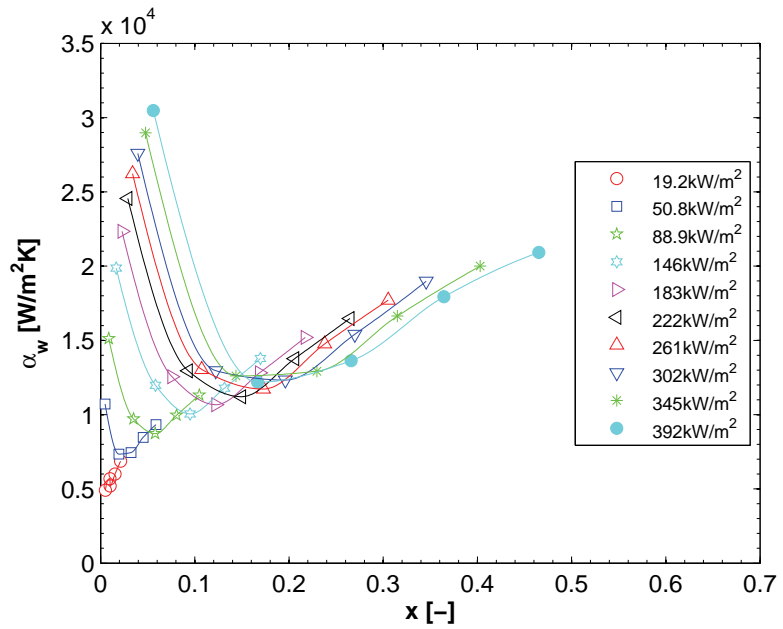

(a) New flow pattern based heat transfer model

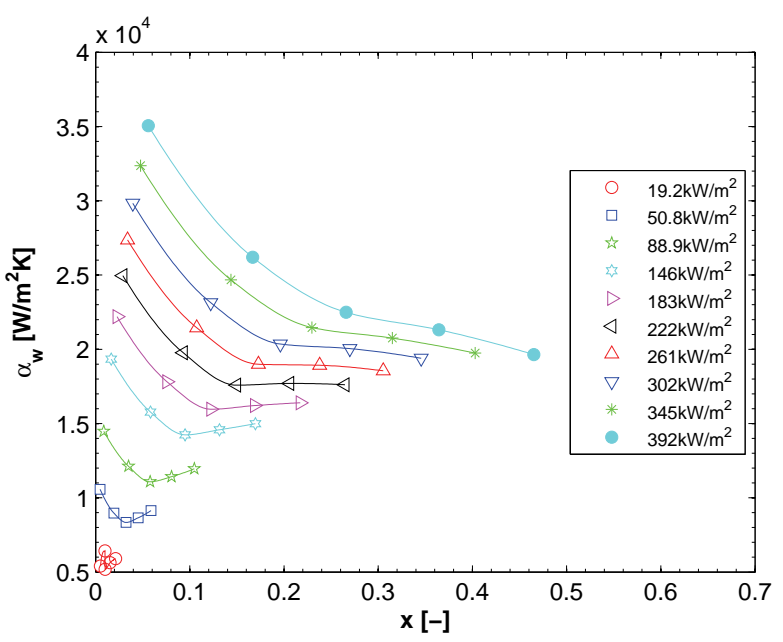

(b) Bertsch et al. (2009)

Fig. 19 Simulated $\alpha_{w}$ for R-134a, $569 \mathrm{~kg} / \mathrm{m}^{2} \mathrm{~s}, \mathrm{~T}_{\text {sat }}=29.9^{\circ} \mathrm{C}$.

$\begin{array}{ll}f & \text { Frictional pressure drop coefficient } \\ d z & \text { Dowstream increment }(\mathrm{m}) \\ e & \text { Thickness }(\mathrm{m}) \\ F & \text { Fin thickness }(\mathrm{m}) \\ G & \text { Mass flux }\left(\mathrm{kg} / \mathrm{m}^{2} \mathrm{~s}\right) \\ g & \text { Earth gravity }\left(9.81 \mathrm{~m} / \mathrm{s}^{2}\right) \\ H & \text { Channel height }(\mathrm{m}) \\ h & \text { Enthalpy }(\mathrm{kJ} / \mathrm{kg}) \\ I B & \text { Isolated bubble flow regime } \\ L & \text { Evaporator length }(\mathrm{m}) \\ l & \text { Heater size }(\mathrm{m}) \\ N & \text { Number of channel } \\ N u_{m} & \text { Mean Nusselt number }\left(\frac{\alpha D}{\lambda}\right) \\ N u_{z} & \text { Local Nusselt number }\left(\frac{\alpha D}{\lambda}\right) \\ P r & \text { Prandtl number }\left(\frac{c \mu}{\lambda}\right) \\ P T a p & \text { Pressure tap position } \\ p & \text { Pressure } \\ q & \text { Heat flux }\left(\mathrm{W} / \mathrm{m}^{2}\right) \\ R e & \text { Reynold numbe }\left(\frac{G D}{\mu}\right) \\ R M S & \text { Root mean square } \\ T & \text { Temperature }\left({ }^{\circ} \mathrm{C}\right) \\ W & \text { Channel width }(\mathrm{m}) \\ x & \text { Vapor quality }\end{array}$

\begin{tabular}{|c|c|}
\hline$z$ & Downstream position (m) \\
\hline$z^{*}$ & Non-dimensional downstream position \\
\hline \multicolumn{2}{|c|}{ Greek Symbols } \\
\hline$\alpha$ & Heat transfer coefficient $\left(\mathrm{W} / \mathrm{m}^{2} \mathrm{~K}\right)$ \\
\hline$\Delta p$ & Pressure drop $(\mathrm{Pa})$ \\
\hline$\delta$ & Liquid film thickness (m) \\
\hline$\eta$ & Fin efficiency \\
\hline$\gamma$ & Aspect ratio (W/H) \\
\hline$\lambda$ & Thermal conductivity $(\mathrm{W} / \mathrm{mK})$ \\
\hline$\mu$ & Dynamic viscosity (Pas) \\
\hline$\rho$ & Density $\left(\mathrm{kg} / \mathrm{m}^{3}\right)$ \\
\hline$v$ & Specific volume $\left(\mathrm{m}^{3} / \mathrm{kg}\right)$ \\
\hline$\xi$ & Pressure drop coefficient \\
\hline \multicolumn{2}{|c|}{ Subscripts } \\
\hline 0 & Initial \\
\hline 1 & Pressure tap 1 \\
\hline 2 & Pressure tap 2 \\
\hline $3 z$ & Three zone model \\
\hline av & Average \\
\hline $\mathrm{b}$ & Base \\
\hline $\mathrm{ch}$ & Channel \\
\hline ch-end & End of Channel \\
\hline evap & Evaporator base \\
\hline $\exp$ & Experimental \\
\hline $\mathrm{f}$ & Fluid \\
\hline film & Liquid film \\
\hline footprint & Footprint area at the root of the fins \\
\hline i & Increment number \\
\hline in & Incoming \\
\hline 1 & Liquid \\
\hline lam & Laminar \\
\hline outlet & Outlet plenum \\
\hline pred & Prediction \\
\hline ref & Reference \\
\hline restr-in & Inlet restriction \\
\hline restr-out & Outlet restriction \\
\hline sat & Saturation \\
\hline TIM & Thermal interface material \\
\hline turb & Turbulent \\
\hline $\mathrm{v}$ & Vapor \\
\hline $\mathrm{w}$ & Wall \\
\hline $\mathrm{x}$ & Row number \\
\hline . & Column number \\
\hline
\end{tabular}

\section{REFERENCES}

Agostini, B., Thome, J., Fabbri, M., Michel, B., Calmi, D., and Kloter, U., 2008, "High Heat Flux Flow Boiling in Silicon Multi-microchannels - Part I: Heat Transfer Characteristics of Refrigerant R236fa," Int J Heat Mass Transfer, 51, 5400-5414. http://dx.doi.org/10.1016/j.ijheatmasstransfer.2008.03.006.

Bao, Z., Fletcher, D., and Haynes, B., 2000, "Flow Boiling Heat Transfer of Freon R11 and HCFC123 in Narrow Passages," Int J Heat Mass Transfer, 43, 3347-3358. http://dx.doi.org/10.1016/S0017-9310(99)00379-8.

Baroczy, C., 1965, "A Systematic Correlation for Two-Phase Pressure Drop," AIChE 8th National Heat Transfer Conference.

Bertsch, S., Groll, E., and Garimella, S., 2009, "A Composite Heat Transfer Correlation for Saturated Flow Boiling in Small Channels," Int J Heat Mass Transfer, 52, 2110-2118. http://dx.doi.org/10.1016/j.ijheatmasstransfer.2008.10.022.

Biber, R., and Belady, L., 1997, "Pressure Drop Prediction for Heat Sinks: What is the Best Method?" INTERpack'97. 
Chisholm, D., 1973, "Pressure Gradients due to Friction during the Flow of Evaporating Two-phase Mixtures in Smooth Tubes and Channels." Int J Heat Mass Transfer, 16, 347-358.

Cicchitti, A., Lombardi, C., Silvestri, M., Soldaini, G., and Zavattarelli, R., 1960, "Two-phase cooling experiments-pressure drop, heat transfer and burnout measurements," Energ Nucl, 7, 407-425.

Cioncolini, A., and Thome, J., 2011, "Algebraic Turbulence Modeling in Adiabatic and Evaporating Annular Two-phase Flow," Int J Heat Fluid Flow, 32, 805-817. http://dx.doi.org/10.1016/j.ijheatfluidflow.2011.05.006.

Cioncolini, A., Thome, J., and Lombardi, C., 2009, "Unified Macro-to-microscale Method to Predict Two-phase frictional Pressure Drops of Annular Flows," Int J Multiphase Flow, 35, 1138-1148. http://dx.doi.org/10.1016/j.ijmultiphaseflow.2009.07.005.

Collier, J., and Thome, J., 1994, Convective Boiling and Condensation, 3rd ed., Oxford University Press, Oxford.

Costa-Patry, E., 2011, Cooling High Heat Flux Micro-electronic Systems using Refrigerants in High Aspect Ratio Multi-microchannel Evaporators, Ph.D. thesis, École Polytechnique Fédérale de Lausanne. http://dx.doi.org/10.5075/epfl-thesis-5225.

Costa-Patry, E., Nebuloni, S., Olivier, J., and Thome, J., 2011a, "On-chip Two-phase Cooling with Refrigerant 85um-wide Multi-microchannel Evaporator under Hot-spot Conditions," Accepted by IEEE Trans Components and Packaging Tech, -, 1-10.

Costa-Patry, E., Olivier, J., Michel, B., and Thome, J., 2011b, "Twophase Flow of Refrigerants in $85 \mu \mathrm{m}$-wide Multi-microchannels: Part II: Heat Transfer with 35 Local Heaters," Int J Heat Fluid Flow, 32(2), 464476. http://dx.doi.org/10.1016/j.ijheatfluidflow.2011.01.006.

Costa-Patry, E., Olivier, J., Nichita, B., Michel, B., and Thome, J., 2011c, "Two-phase Flow of Refrigerants in $85 \mu \mathrm{m}$-wide Multimicrochannels: Part I: Pressure Drop," Int J Heat Fluid Flow, 32(2), 451-463. http://dx.doi.org/10.1016/j.ijheatfluidflow.2011.01.005.

Dupont, V., Thome, J., and Jacobi, A., 2004, "Heat Transfer Model for Evaporation in Microchannels. Part II: Comparison with the Database," Int J Heat Mass Transfer, 47, 3387-3401. http://dx.doi.org/10.1016/j.ijheatmasstransfer.2004.01.007.

Idelcik, I., 1999, Memento des pertes de charge, Eyrolles, Paris.

Kline, S., and McClintock, F., 1953, "Describing Uncertainties in Singlesample Experiments," Mech Eng, 75, 3-8.

Koomey, J., Belady, C., Patterson, M., Santos, A., and K.D., L., 2009, "Assessing Trends over Time in Performance, Costs, and Energy Use for Servers," Tech. rep., Lawrence Berkeley National Laboratory and Stanford University.

Kreith, F., and Bohn, M., 2001, Principles of Heat Transfer, sixth ed., Brooks/Cole, Pacific Grove USA.

Lazarek, G., and Black, S., 1982, "Evaporative Heat Transfer, Pressure Drop and Critical Heat Flux in a small vertical Tube with R-113," Int J Heat Mass Transfer, 25(7), 945-960.

Lee, J., and Mudawar, I., 2005a, "Two-phase Flow in High-heat-flux Micro-channel Heat Sink for Refrigeration Cooling Applications: Part I - Pressure Drop Characteristics," Int J Heat Mass Transfer, 48, 928-940. http://dx.doi.org/10.1016/j.ijheatmasstransfer.2004.09.018.
Lee, J., and Mudawar, I., 2005b, "Two-phase Flow in High-heat-flux Micro-channel Heat Sink for Refrigeration Cooling Applications: Part II - Heat Transfer Characteristics," Int J Heat Mass Transfer, 48, 941-955. http://dx.doi.org/10.1016/j.ijheatmasstransfer.2004.09.018.

Lee, P.S., and Garimella, S., 2008, "Saturated Flow Boiling Heat Transfer and Pressure Drop in Silicon Microchannel Arrays," Int J Heat Mass Transfer, 51, 789-806. http://dx.doi.org/10.1016/j.ijheatmasstransfer.2007.04.019.

Lin, S., Kew, P., and Cornwell, K., 2001, "Two-phase Heat Transfer to a Refrigerant in a $1 \mathrm{~mm}$ Diameter Tube," Int J Refrigeration, 24, 51-56. http://dx.doi.org/10.1016/S0140-7007(00)00057-8.

Lockhart, R., and Martinelli, R., 1949, "Proposed Correlation of Data for Isothermal Two-phase, Two-component Flow in Pipes," Chem Eng Prog, 45, 39-48.

Olivier, J., 2009, Single-phase Heat Transfer and Pressure Drop of Water Cooled at a Constant Wall Temperature inside Horizontal Circular Smooth and Enhanced Tubes with Different Inlet Configurations in the Transitional Flow Regime, Ph.D. thesis, University of Pretoria.

Ong, C., and Thome, J., 2011a, "Macro-to-microchannel Transition in Two-phase Flow: Part 1 - Two-phase Flow Patterns and Film Thickness Measurements," Exp Therm Fluid Science, 35, 37-47. http://dx.doi.org/10.1016/j.expthermflusci.2010.08.004.

Ong, C., and Thome, J., 2011b, "Macro-to-microchannel Transition in Two-phase Flow: Part 2 - Flow Boiling Heat Transfer and Critical Heat Flux," Exp Therm Fluid Science. http://dx.doi.org/10.1016/j.expthermflusci.2010.12.003.

Park, J., and Thome, J., 2010, "Critical Heat Flux in Multi-microchannel Copper Elements with Low Pressure Refrigerants," Int J Heat Mass Transfer, 53, 110-122, doi:http://dx.doi.org/10.1016/j.ijheatmasstransfer.2009.09.047.

http://dx.doi.org/10.1016/j.ijheatmasstransfer.2009.09.047.

Pethukov, B., 1970, "Heat Transfer and Friction in Turbulent Pipe Flow with Variable Properties," Adv. Heat Transfer vol.6, Academic Press.

Shah, R., and London, A., 1978, Laminar Flow Forced Convection in Ducts, Academic Press, London.

Thome, J., and Consolini, L., 2009, "Mechanisms of Boiling in MicroChannels: Critical Assessment," Heat Transfer Eng, 31(4), 288-297. http://dx.doi.org/10.1080/01457630903312049.

Thome, J., Dupont, V., and Jacobi, A., 2004, "Heat Transfer Model for Evaporation in Microchannels. Part I: Presentation of the Model," Int J Heat Mass Transfer, 47, 3387-3401. http://dx.doi.org/10.1016/j.ijheatmasstransfer.2004.01.006.

Tran, T., Wambsganss, M., and France, D., 1996, "Small Circular- and Rectangular-channel Boiling with Two Refrigerants," Int J Multiphase Flow, 22(3), 485-498. http://dx.doi.org/10.1016/0301-9322(96)00002-X.

Zivi, S., 1964, "Estimation of Steady-state Stem Void-fraction by Means of the Principle of Minimum Entropy Production," J Heat Transfer, 86, 247-252. 